MIGUEL EDGAR MORALES UDAETA

NOVOS INSTRUMENTOS DE PLANEJAMENTO ENERGÉTICO E O DESENVOLVIMENTO SUSTENTÁVEL - PLANEJAMENTO INTEGRADO DE RECURSOS ENERGÉTICOS NA USP

Pesquisa Científica Realizada e Ferramentas Metodológicas Consolidadas do PIRnaUSP Aplicadas à RAA

Tese de Livre-Docência apresentada à Escola Politécnica da Universidade de São Paulo para obtenção do título de Livre-Docente. 
MIGUEL EDGAR MORALES UDAETA

\section{NOVOS INSTRUMENTOS DE PLANEJAMENTO ENERGÉTICO E O DESENVOLVIMENTO SUSTENTÁ VEL - PLANEJAMENTO INTEGRADO DE RECURSOS ENERGÉTICOS NA USP}

Pesquisa Científica Realizada e Ferramentas Metodológicas Consolidadas do PIRnaUSP Aplicadas à RAA

Tese de Livre-Docência apresentada à Escola Politécnica da Universidade de São Paulo para obtenção do título de Livre-Docente.

Área: Energia Elétrica

Departamento de Engenharia de Energia e Automação Elétricas - PEA

Revisão de texto: Cristiane Garcia

São Paulo

2012 


\section{FICHA CATALOGRÁFICA}

Udaeta, Miguel Edgar Morales

Novos Instrumentos de Planejamento Energético e o Desenvolvimento Sustentável - Planejamento Integrado de Recursos energéticos na USP: Pesquisa Científica Realizada e Ferramentas Metodológicas Consolidadas do PIRnaUSP Aplicadas à RAA/ Miguel Edgar Morales Udaeta - São Paulo, 2012.

$125 \mathrm{f}$

Tese (Livre Docência - Área: Energia Elétrica) - Escola Politécnica da Universidade de São Paulo. Departamento de Engenharia de Energia e Automação Elétricas.

1. Planejamento Energético 2. PIR 3. Desenvolvimento Sustentável. I. Título. 
Ao buraco negro perdido no espaço sideral. 


\section{AGRADECIMENTOS}

À FAPESP (Processo 03/064441-7). Ao PRH-ANP/04. Aos professores do PEA. Ao IEE. À EPUSP. À Cooperhidro. À Unisalesiano.

Aos da equipe de trabalho dedicada a parir o Planejamento Integrado de Recursos Energéticos para o Desenvolvimento Sustentável (PIRnaUSP, para os mais chegados) que, ao longo desses anos, determinou a possibilidade real de as coisas acontecerem, ou seja, aos EnIn do PIRnaUSP - uns mais do que outros, outros mais ainda, porém todos necessários, pois esta obra é deles e sem eles esta não existiria; tais são (perdão se algum nome fugiu da memória): Alexandre Malta Tedaldi; Alexandre Orrico Reinig; André Luiz Veiga Gimenes; Antonio Gomes dos Reis; Barnabé da Silva Junior; Carlos Antonio Farias de Souza; Daniele Lopes Freitas; Décio Cicone Junior; Fatuma Catherine Atieno Odongo; Felipe Coelho Costa; Felipe Iwamoto; Fernando Muccioli de Mello; Flávio Marques Azevedo; Geraldo Francisco Burani; Ginaldo Vasconcelos Filho; Isabel Akemi Bueno Sado; Janaína Roldão de Souza; José Aquiles Baesso Grimoni; Júlia Marques Bellacosa; Luiz Cláudio Ribeiro Galvão; Marina Martins Marques de Souza; Mário Fernandes Biague; Martim Debs Galvão; Natálya Gonçalves Kadri; Nelson Hitoshi Takiy; Pascoal Henrique da Costa Rigolin; Paulo Hélio Kanayama; Paulo Roberto Carneiro; Rafael Augusto Possari; Rafael Bragança de Lima; Rafael Makiyama; Renata Valério de Freitas; Ricardo Junqueira Fujii; Ricardo Lacerda Baitelo; Rodrigo Antônio Carneiro; Thadeu Hiroshi Ferraz; Vanessa Meloni Massara; Victor Takazi Katayama. Em especial ao Jonathas Bernal pela dedicação sem condições na produção deste trabalho. 


\section{RESUMO}

Este trabalho tem por objetivo desenvolver novos instrumentos de planejamento energético tal que o desenvolvimento sustentável seja possível, tendo como marco de referência a determinação, em primeira instância, de modelos, procedimentos, metodologias e ferramentas intrínsecas ao Planejamento Integrado de Recursos energéticos (PIR) como instrumento da sustentabilidade do desenvolvimento. Metodologicamente repousa na busca da aplicação do PIR, tendo como meta colocar em evidência o desenvolvimento sustentável regional com base na realização de um projeto de pesquisa científica na engenharia aprovado pela Fapesp. Nesse sentido, estabelece-se a RAA/SP, conhecida como Oeste Paulista, para a realização do PIR, identificando necessidades ou expectativas energéticas e estratégicas da região e contando com a participação dos atores locais e a consideração plena dos custos completos dos recursos.

Os resultados dos trabalhos de pesquisa estão evidenciados em projetos de formatura, dissertações, teses e publicação de artigos técnico-científicos. Mais ainda, são resultados do trabalho a consolidação e a verificação das ferramentas metodológicas de todas as partes do PIRnaUSP, tais como: o CVPC dos Recursos Energéticos; o Mapeamento Energoambiental; a Modelagem da inclusão dos Atores através do Ranqueamento dos Recursos Energéticos; e a Modelagem da Integração do Recursos Energéticos considerando os Vigilantes a longo do tempo e da geografia (física e humana). Desses resultados conclui-se que o trabalho desenvolvido, teórico-acadêmico e prático in loco, demonstra a consolidação do PIR como instrumento para o desenvolvimento sustentável e também sua concepção modular para aplicação real, tendo como alicerce o uso de ferramentas metodológicas que consideram as dimensões do desenvolvimento permanentemente, isto é, as dimensões técnico-econômica, ambiental, social e política. 


\section{ABSTRACT}

The objective of this work is the development of a suite of new tools for energy planning under sustainable development paradigm, considering models, procedures and methodologies a priori. Methodologically, the suite of new tools lies on using PIR (portuguese acronym for Integrated energy Resources Planning), targeting regional sustainable development, which was previously approved by Fapesp. In line with the proposed previously: (i) it was chosen the RAA (acronym in Portuguese for Administrative Region of Araçatuba, west of the state of São Paulo, Brazil) as the study case region; (ii) Engaged the local stakeholders, and identified their demands and strategic expectations regarding energy, always considering the full costs account of energy resources.

The results of the researches are evidenced by the production of undergraduate academic projects, dissertations, doctoral theses, as well as technical-scientific papers in published in journals. Moreover, can be considered as results of research the suite of tools, and it is highlighted the following tools: (i) the CVPC (the Portuguese acronym for Computation and Valuation of Full Potential Account) of the energy resources; (ii) energyenvironmental mapping; (iii) the modeling and inclusion of the stakeholders into a energy resources ranking process; (iv) and the modeling and integration of energy resources, considering a set of vigilantes along the timeline and within the specific ( physical and human) geography. From these results it can be concluded that the work, of the theoreticalacademic and field researches point of view, shows the consolidation of the PIR as the tool for sustainable development; in addition its modular design conception is applicable in real scale, taking as basis the use of methodological tools that consider permanently the dimensions of development, that is the tech-economical, environmental, social and political dimensions. 


\section{LISTA DE SIGLAS, ACRÔNIMOS E ABREVIATURAS}

$\mathrm{ACC}$

ADCC

AGRENER

AHCC

ANP

CBPE

CERPCH

Cetesb

CH4

CLAGTEE

Cooperhidro

COPPE

CVPC

DBO

DL

DSM

EIA/RIMA

En-In

EPUSP

Fapesp

GD

GEE

Gepea

GLD

GLO

IAEE

IAPG

IBP

ICEE

IDH

IEE

INEER
Avaliação dos Custos Completos

Avaliação Determinística dos Custos Completos

Encontro de Energia no Meio Rural

Avaliação Holística dos Custos Completos

Agência Nacional de Petróleo, Gás Natural e Biocombustíveis

Congresso Brasileiro de Planejamento Energético

Centro Nacional de Referência em Pequenas Centrais Hidrelétricas

Companhia de Tecnologia de Saneamento Ambiental

Metano

Congresso Latino-Americano de Geração e Transmissão de Energia Elétrica

Cooperativa do Polo Hidroviário de Araçatuba

Instituto A. L. Coimbra de Pós-Graduação e Pesquisa de Engenharia

Cômputo e Valoração do Potencial Completo

Demanda Bioquímica de Oxigênio

Decision Lens

Demand Side Management

Estudo de Impacto Ambiental/Relatório de Impacto Ambiental

Envolvidos e Interessados

Escola Politécnica da Universidade de São Paulo

Fundação de Amparo à Pesquisa do Estado de São Paulo

Geração Distribuída

Gases de Efeito Estufa

Grupo de Energia do PEA

Gerenciamento do Lado da Demanda

Gerenciamento do Lado da Oferta

International Association for Energy Economics

Instituto Argentino del Petróleo y del Gas

Instituto Brasileiro de Petróleo, Gás e Biocombustíveis

International Conference on Engineering Education

Índice de Desenvolvimento Humano

Instituto de Eletrotécnica e Energia

International Network for Engineering Education \& Research 


$\begin{array}{ll}\text { IQR } & \text { Índice de Qualidade de Aterro } \\ \text { IRP } & \text { Integrated Resource Planning } \\ \text { LEAP } & \text { Long-range Energy Alternative Planning } \\ \text { MP } & \text { Material Particulado } \\ \text { NIPE } & \text { Núcleo Interdisciplinar de Planejamento Energético } \\ \text { O3 } & \text { Ozônio } \\ \text { OCDE } & \text { Organização para o Desenvolvimento Econômico } \\ \text { ONG } & \text { Organização Não Governamental } \\ \text { PAH } & \text { Processo Analítico Hierárquico } \\ \text { PCH } & \text { Pequena Central Hidrelétrica } \\ \text { PEA } & \text { Departamento de Engenharia de Energia e Automação Elétricas - EPUSP } \\ \text { PH } & \text { Potencial Hidrogeniônico } \\ \text { PIB } & \text { Produto Interno Bruto } \\ \text { PIR } & \text { Planejamento Integrado de Recursos energéticos } \\ \text { PIRnaUSP } & \text { Planejamento Integrado de Recursos energéticos na USP } \\ \text { PRH } & \text { Programa de Recursos Humanos } \\ \text { RAA } & \text { Região Administrativa de Araçatuba } \\ \text { RE } & \text { Recurso Energético } \\ \text { RELD } & \text { Recursos Energéticos do Lado da Demanda } \\ \text { RELO } & \text { Recursos Energéticos do Lado da Oferta } \\ \text { RTC } & \text { Relatório Técnico-científico } \\ \text { SBPE } & \text { Sociedade Brasileira de Planejamento Energético } \\ \text { SEEDS } & \text { Seção de estudos estratégicos de desenvolvimento sustentável - GEPEA } \\ \text { UFRJ } & \text { Universidade Federal do Rio de Janeiro } \\ \text { UGRHI } & \text { Unidade de Gerenciamento de Recursos Hídricos } \\ \text { UHE } & \text { Usina Hidrelétrica } \\ \text { Unicamp } & \text { Universidade Estadual de Campinas } \\ \text { Unisalesiano } & \text { Centro Universitário Católico Salesiano Auxilium } \\ \text { UNMDP } & \text { Universidad Nacional de Mar del Plata } \\ \text { USP } & \text { Universidade de São Paulo } \\ \text { VOHC } & \text { Volatile Organic Hydro Carbons } \\ & \end{array}$




\section{LISTA DE FIGURAS}

Figura 1: Modelagem Fundamental do Processo de PIRnaUSP ........................................... 13

Figura 2: Diagrama Esquemático do Planejamento Integrado de Recursos energéticos ........ 15

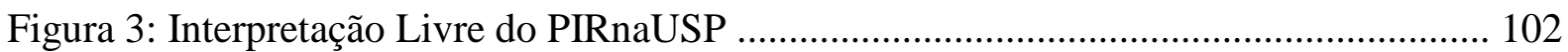




\section{Índice}

Introdução

1.1 Preâmbulo 3

1.2 Contexto e Síntese ___ 5

Objetivos do Projeto___ 8

2.1 Objetivos Gerais_________________ 9

2.2 Objetivos Específicos ___ 10

$3 \quad$ Planejamento Integrado de Recursos Energéticos na USP_ 11

Realizações de Consolidação do PIRnaUSP _ 16

4.1 Introdução______ 16

4.2 Inventário Ambiental (energético) Prévio ___ 18

4.2.1 Tese de Doutorado _ 20

4.3 Listagem, Peneiramento e Seleção dos Recursos Energéticos ___ 22

4.3.1 Dissertações de Mestrado __ 25

4.4 Ferramentas de Suporte ao PIR (PIRnaUSP) ___ 27

4.4.1 Tese de Doutorado em Andamento________ 28

4.5 Envolvidos e Interessados (En-In) ___ 28

4.6 Caracterização de Recursos Energéticos ___ 30

4.6.1 Recursos Energéticos do Lado da Oferta - RELO ___ 30

4.6.2 Recursos Energéticos do Lado da Demanda - RELD___ 31

4.6.3 Dissertação de Mestrado em Andamento _____ 34

4.7 Cômputo e Valoração do Potencial Completo (CVPC) ___ 34

4.7.1 Tese de Doutorado _____ 35

4.8 Avaliação dos Custos Completos - ACC __ 36

4.8.1 Dissertação de Mestrado____ 39

4.8.2 Ranqueamento de Recursos Energéticos ____ 40

4.8.3 Tese de Doutorado em Andamento____ 41

4.8.4 Trabalho Final de Graduação ____ 41

4.9 Mapeamento Regional Pró-Energético ___ 42

4.9.1 Trabalhos Finais de Graduação____ 45

4.10 Balanço Energoambiental da RAA___ 49

4.11 Previsão de Demanda no PIRnaUSP ___ 50

4.11.1 Cenários Energéticos____ 51

4.11.2 Cenários Socioeconômicos__________________ 52

4.11.3 Dissertações de Mestrado ___ 54 
4.12 Integração de Recursos dentro do PIRnaUSP _ 55

4.13 Plano Preferencial no PIR___ 56

4.13.1 Tese de Doutorado __ 57

4.14 Plano de Negócios Cliente do PIRnaUSP ___ 59

4.14.1 Dissertação de Mestrado em Andamento ___ 59

$5 \quad$ Contribuição da Cooperhidro para o PIRnaUSP 61

5.1 A instituição ___ 61

5.2 A Intersecção de Interesses na Região de Araçatuba ___ 61

5.3 A Cooperhidro no Projeto FAPESP 03/06441-7 ___ 62

6 Transferência de Conhecimento e Formação Especializada _ 64

6.1 Oficinas e Treinamentos Técnicos de PIRnaUSP ___ 64

6.2 Efeito Local - Simpósios de Água e Energia ___ 65

$7 \quad$ Políticas Públicas___ 66

$8 \quad$ Produção Técnico-científica do PIRnaUSP__ 67

8.1 Teses e doutores ___ 67

8.2 Dissertações e mestres ___ 69

8.3 Trabalhos de Formatura e Graduados___ 70

8.4 Iniciação Científica e Pesquisador ____ 78

8.5 Publicações em Periódicos (Anexo A1)____ 84

8.6 Anais de Congressos (Anexo A2) __ 86

8.6.1 Internacionais ___ 86

8.6.2 Nacionais _ 89

8.7 Artigos em Mídia Aberta da Região (Anexo A3)_____ 93

8.8 Documentos do Arquivo da Cooperhidro __ 95

9 Conclusão___ 97

$10 \quad$ Referências Bibliográficas _ 103 


\section{Introdução}

\subsection{Preâmbulo}

A iniciação na construção e arquitetura dos novos instrumentos de planejamento energético demanda evidenciar que originalmente o PIR (Planejamento Integrado de Recursos) está diretamente relacionado ao IRP (da sigla, em inglês, "Integrated Resource Planning"). O IRP é resultado do aprimoramento do Planejamento no contexto dos sistemas elétricos de potência, com base no desenvolvimento deste nos Estados Unidos da América (UDAETA, 1997). Assim, é interessante mencionar que o IRP resulta do planejamento conhecido como "Least Cost Power Planning", que vem a ser, grosso modo, a referência teórico-prática do planejamento energético no Brasil - e, em geral, do mundo.

No contexto desta iniciação, sob o olhar de um leigo em PIR, pode-se afirmar que nos debruçamos num Planejamento Integrado de Recursos do Setor Energético referenciado prévia e posteriormente à energia elétrica. Nessa medida, o PIR consiste em um conjunto de estratégias que genericamente visam o desenvolvimento energético de uma região (país ou alguns países, estado ou alguns estados, município ou alguns municípios etc.), tendo como bandeira principal a sustentabilidade. As implementações de fontes energéticas devem variar de acordo com as características de cada região e do momento em que são consideradas; isso é levado em consideração no PIR com uma caracterização concisa das condições ambientais, sociais, políticas e econômicas. Essa caracterização demonstra o caráter sustentável do PIR, pois, quando são levados em consideração todos esses quesitos, mostra-se um desenvolvimento mais consistente.

Na caracterização ambiental, são apontadas informações sobre o clima, a vegetação, a biodiversidade e as águas superficiais e subterrâneas da região, além de outras informações convenientes. São também analisados a infraestrutura, a economia e os aspectos 
demográficos, que são de suma importância para entender como seria a aceitação da implementação de estratégias no local em estudo.

Com as características da região, os recursos energéticos a serem aplicados são listados, peneirados e selecionados. O PIR, aqui se destaca, por adotar a ACC (Avaliação de Custos Completos), que serve de ferramenta para diferenciar os recursos, levando em consideração as variáveis já citadas: impactos ambiental, social, político e econômico. Na listagem de recursos, não se descarta prontamente um recurso por, na atualidade, ser negativamente impactante em algum dos quesitos, pois, no PIR, as possibilidades são analisadas em um horizonte de maior de tempo. Assim, um recurso muito difícil de implementar na atualidade pode, com o tempo, ter o seu impacto negativo diminuído.

São feitos levantamentos de dados quanto aos recursos energéticos atuais, como a demanda, as fontes e os usos finais, o que auxilia na tomada de decisões. No PIR, os recursos energéticos, do lado da demanda e do lado da oferta, são colocados juntos, como possibilidades de implementações, o que expande o conceito de implementação de recursos. A curva da oferta deixa de ser apenas uma seguidora da curva da demanda. Elas são estudadas como um todo e são adaptadas uma em função da outra e ambas em função das variáveis ambiental, social, política e econômica.

A análise feita, que aborda a situação social e política, abre a possibilidade de apoio de empresas, prefeituras, governos e ONGs, envolvidos e interessados no desenvolvimento da região em estudo. As empresas interessadas podem dar auxílio de grande importância para os levantamentos de dados e para a implementação das estratégias. Mudanças de comportamento, por exemplo, incentivadas por palestras ou outros meios, são de grande valia para uma melhoria na demanda energética na região. Assim, o apoio das empresas deixa de se resumir a investimentos financeiros. 
Com os recursos listados e ranqueados, os cenários são gerados a partir das tendências das aplicações. Com isso, e o posicionamento de empresas envolvidas e interessadas e de especialistas, os recursos são escolhidos e segue-se para a fase de integração destes na complexidade que introduz incertezas e riscos no longo prazo, tal que sua implementação seja reavaliada permanentemente na evidência do plano preferencial resultante $\mathrm{e}$ dos requerimentos dos tomadores de decisão.

\subsection{Contexto e Síntese}

As atividades de transformação e de produção requerem energia para sua realização. $\mathrm{O}$ aumento dessas atividades tem feito a demanda humana por energia crescer a níveis que tornaram crítica a questão da obtenção e oferta de recursos energéticos. Não obstante, toda forma de uso da energia implica em impactos diversos que vão além do âmbito do uso em si. Questões como estas justificam a pesquisa por uma abordagem abrangente e mais adequada do planejamento energético.

Garantir e assegurar que a energia esteja disponível a cada momento, de maneira a salvaguardar o futuro da economia, do meio ambiente e da sociedade como um todo é um desafio constante e premissa do desenvolvimento sustentável. Dessa forma, todos os fatores envolvidos para garantir a segurança de suprimento energético ao longo do tempo devem ser de enorme preocupação de todos os segmentos da sociedade, assim como o planejamento do abastecimento e do uso da energia (Recursos Energéticos do Lado da Oferta - RELOs e Recursos Energéticos do Lado da Demanda - RELDs), observando-se todos os atores implicantes de forma inter-relacionada, tais como: fontes, consumidores, usos etc. e as interações entre esses elementos. 
O Planejamento Integrado de Recursos Energéticos (PIR) é uma ferramenta que visa o auxílio à tomada de decisão em busca do melhor aproveitamento dos recursos energéticos (na geografia e no tempo), de forma a concatenar o máximo de variáveis e parâmetros envolvidos em uma análise sistêmica, holística e racional dos recursos energéticos e da região de estudo.

Na busca de uma análise plena de sistemas complexos, a estratégia do PIR consiste em trabalhar as diversas linhas do conhecimento, para que os diferentes enfoques e entendimentos sobre o meio sejam contemplados na Integração dos Recursos pesquisados e avaliados para esse fim. Unificar diversas linguagens e pensamentos determinísticos apresenta-se como o maior desafio do Planejamento na busca do desenvolvimento sustentável.

A sustentabilidade pode ser descrita como um propósito de bem-estar geral, dentro das possibilidades e realidades da sociedade, ou também como o fechamento do ciclo de produção, com o mínimo de produtos secundários, a máxima eficiência dos processos e a ótima manutenção dos recursos. Estes objetivos estariam integrados como um plano para o suprimento das necessidades futuras de energia, com a minimização dos impactos socioambientais gerados e o máximo atendimento às prerrogativas regionais.

O PIR como metodologia permeia diversas áreas do conhecimento, expressas pelas dimensões ambientais, políticas, sociais e técnico-econômicas, e atua no emprego de análises técnicas e ferramentas matemáticas que configuram o seu caráter sistêmico. Todo o processo pode ser observado segundo essas divisões em frentes sinérgicas de trabalho, como, por exemplo, a classificação a priori dos RELDs e dos RELOs, que são analisados sistemática e separadamente e, em um primeiro momento, existem como produtos isolados; por conseguinte, trabalha-se a Integração com a extinção desse formato bilateral, entretanto, não haveria posterior integração sem uma dessas análises.

Assim sendo, a tese PIR expressada neste documento, que especialmente também é denominada de PIRnaUSP pelas especificidades e diferenciações em relação ao PIR como 
originalmente disseminado no Brasil (fundamentalmente na década de 1990; explicitado inicialmente no item intitulado "Prólogo"), permeia sinergicamente a realização de atividades de pesquisa baseadas no projeto FAPESP 03/06641-7 (fixada na RAA/SP) no sentido de consolidar o PIR e suas ferramentas como novos instrumentos de planejamento energético e para o desenvolvimento sustentável. Nesse sentido, a caracterização dos recursos e dos aproveitamentos energéticos na região foco do estudo (Oeste Paulista - RAA) levam em consideração a sua localização, a disponibilidade e o interesse de exploração, bem como seus impactos em todas as dimensões de análise do PIR.

A Região Administrativa de Araçatuba (RAA) no Estado de São Paulo tem como uma das principais características de sua atividade econômica a exportação de energia, representada pelo etanol, pela passagem do gasoduto Brasil-Bolívia, pela localização de cinco das maiores usinas hidrelétricas do Estado e pela sede da maior empresa produtora de coletores solares do país. A região ainda é entrecortada por grandes rios navegáveis, formando a hidrovia Tietê-Paraná, permitindo ainda a ligação hidroviária com os rios Grande e Piracicaba, de grande importância econômica para o Estado. 


\section{Objetivos do Projeto}

Realizar estudos em planejamento energético de longo prazo, visando o desenvolvimento sustentável, com o intuito de identificar e avaliar a partir da aplicação numa região piloto os recursos energéticos (do lado da oferta e da demanda) disponíveis nessa região e, principalmente, realizar o Planejamento Integrado de Recursos Energéticos (PIR);

Desenvolver novos instrumentos de planejamento energético, de forma que o desenvolvimento sustentável seja possível, tendo como marco de referência a determinação, em primeira instância, de modelos, procedimentos, metodologias e ferramentas intrínsecas ao Planejamento Integrado de Recursos energéticos (PIR) como instrumento da introdução dos conceitos difusos de sustentabilidade no processo de desenvolvimento real;

Aplicar o PIR em tempo, matéria e geografia, tendo como meta evidenciar o desenvolvimento sustentável regional, fundamentalmente com base na realização de um projeto de pesquisa científica em engenharia aprovado pela FAPESP.

Nesse sentido, os trabalhos comportam e ensejam a procura pelo desenvolvimento sustentável para a Região Oeste de São Paulo, através da elaboração e implantação de um PIR (Planejamento Integrado de Recursos energéticos) com a aplicação de etapas como: Inventário Energo-Ambiental; Caracterização de Recursos Energéticos do Lado da Oferta e do Lado da Demanda, através do Cômputo e Valoração do Potencial Completo desses recursos; Construção de Cenários Energéticos e Previsão de Demanda; Mapeamento Energoambiental da Região Administrativa de Araçatuba; Integração de Recursos; Elaboração de um Plano Preferencial. Cabe ressaltar que essas etapas formam parte também das principais metas do PIR para a RAA. 
Outros objetivos referem-se a realizar a avaliação da exequibilidade do uso do potencial energético local e a consolidação da participação dos envolvidos e interessados (prefeituras, secretarias de Energia, Planejamento e Meio Ambiente, governo do Estado, investidores, usuários de energia, ONGs, sindicatos e sociedade organizada), em projetos relacionados à implantação do processo de PIR;

Investigar e identificar as necessidades ou expectativas estratégicas da região, capacitando equipes e consolidando relacionamentos com entidades parceiras na região. Além de identificar inclusive possíveis negócios em recursos energéticos locais distribuídos, avaliando o potencial econômico desses recursos e, se plausível, a captação de projetos estratégicos para o desenvolvimento regional.

Assim sendo, nos itens a seguir são mencionados os objetivos gerais e específicos da pesquisa, na sua performance real, haja vista a complexidade, interdisciplinaridade e multiplicidade de atores evidenciada pelo PIR da RAA.

\subsection{Objetivos Gerais}

- Consolidar a caracterização do potencial dos recursos energéticos de energia;

- Aplicar a metodologia do PIR para o potencial energético identificado através dos RELOs (Recursos Energéticos do Lado da Oferta) e dos RELDs (Recursos Energéticos do Lado da Demanda);

- Avaliar a exequibilidade do uso do potencial energético local e realizar e consolidar a participação dos envolvidos e interessados (En-In) em projetos relacionados à implantação do processo de PIR. 


\subsection{Objetivos Específicos}

- Capacitar a equipe da entidade parceira a identificar recursos de oferta e de demanda, viabilizar os recursos locais distribuídos e avaliar o potencial deles visando o desenvolvimento regional;

- Levantar e caracterizar os aproveitamentos energéticos (do lado da oferta e do lado da demanda) e as tecnologias vinculadas a eles;

- Identificar as necessidades ou as expectativas estratégicas;

- Inter-relacionar as informações obtidas e indicar as possibilidades de aproveitamento energético disponíveis (sempre dentro do GLO - Gerenciamento do Lado da Oferta e GLD - Gerenciamento do Lado da Demanda, em equilíbrio);

- Difundir informações sobre a possibilidade do uso dos recursos energéticos de oferta e demanda na região;

- Realizar uma análise para possível modelagem geoenergética;

- Considerar o aproveitamento da geração distribuída como vetor de otimização dos sistemas de transmissão e distribuição;

- Analisar impactos ambientais locais do potencial energético regional;

- Estudar a demanda reprimida e previsão da energia e capacidade necessárias para atender as necessidades futuras de energia. 


\section{Planejamento Integrado de Recursos Energéticos na USP}

A execução do Planejamento Integrado de Recursos energéticos - PIR, tal como metodologicamente vem sendo desenvolvido na USP, com base no projeto FAPESP 03/06441-7 em questão, denomina-se PIRnaUSP. Entretanto, esse PIR não existe no ambiente pregresso (nem no Brasil nem fora), ele nasceu não apenas para ser vontade do estado, ou só de aplicação pública, e sim aberto, manuseável e adaptável a uma ou várias entidades (empresarial, corporativa, não governamental, estatal, local etc.) e em tempo e geografia variáveis. Porém, funciona a longo prazo, pois não trata a operação de fato do sistema, mas sim trabalha cenários - não apenas demanda de mercado, como também local, regional, nacional, supranacional, estadual, área de influência concessível etc.

Assim, pode-se dizer que o PIRnaUSP não é IRP (Integrated Resource Planning), embora tenha seus alicerces nele, nem só DSM (Demand Side Management), apesar de os RELDs (Recursos Energéticos do Lado Demanda) do PIRnaUSP fundamentarem-se essencialmente nela. De fato, deve-se enfatizar que evoluímos para o Planejamento Integrado de Recursos energéticos (PIRnaUSP) modular em todas as suas etapas e como ferramenta ao tomador de decisão variável. Pode-se, então, pôr em evidência as partes modulares que de fato compõem o PIR, validadas no contexto da realização do presente trabalho, que são:

Inventário energoambiental (quando não sistemicamente disponível, supõe-se existente);

$\checkmark$ Determinação geral dos RELOs e RELDs;

$\checkmark$ CVPC (Cômputo e Valoração do Potencial Completo) dos Recursos Energéticos para o PIR (após o peneiramento [UDAETA, 1997]); 
$\checkmark$ Ranqueamento dos REs que implica na realização da ACC (Avaliação dos Custos Completos) e da efetiva interação com os En-In (Envolvidos-Interessados);

$\checkmark$ Mapeamento Energoambiental (fotografia dos meios terrestre, aquático, aéreo e antrópico, em tempo e geografia específicos);

$\checkmark$ Previsão das Necessidades de Energia (Cenários e Mercado/Demanda); Integração dos Recursos Energéticos (considerando os Vigilantes e o estabelecimento do Potencial completo Efetivo dos Recursos Energéticos ou Potencial Realizável Efetivo);

$\checkmark$ Plano Preferencial Integrado de Recursos Energéticos (Carteiras de Recursos e Opções Reais);

$\checkmark$ Plano de Ação (Determinação do Potencial de Mercado dos Recursos), que possibilita também a construção do plano de negócios de um ou mais recursos energéticos efetivamente disponíveis.

Para entender o PIRnaUSP, essas etapas podem ser bem observadas a partir do modelo fundamental, como se observa na Figura 1. 


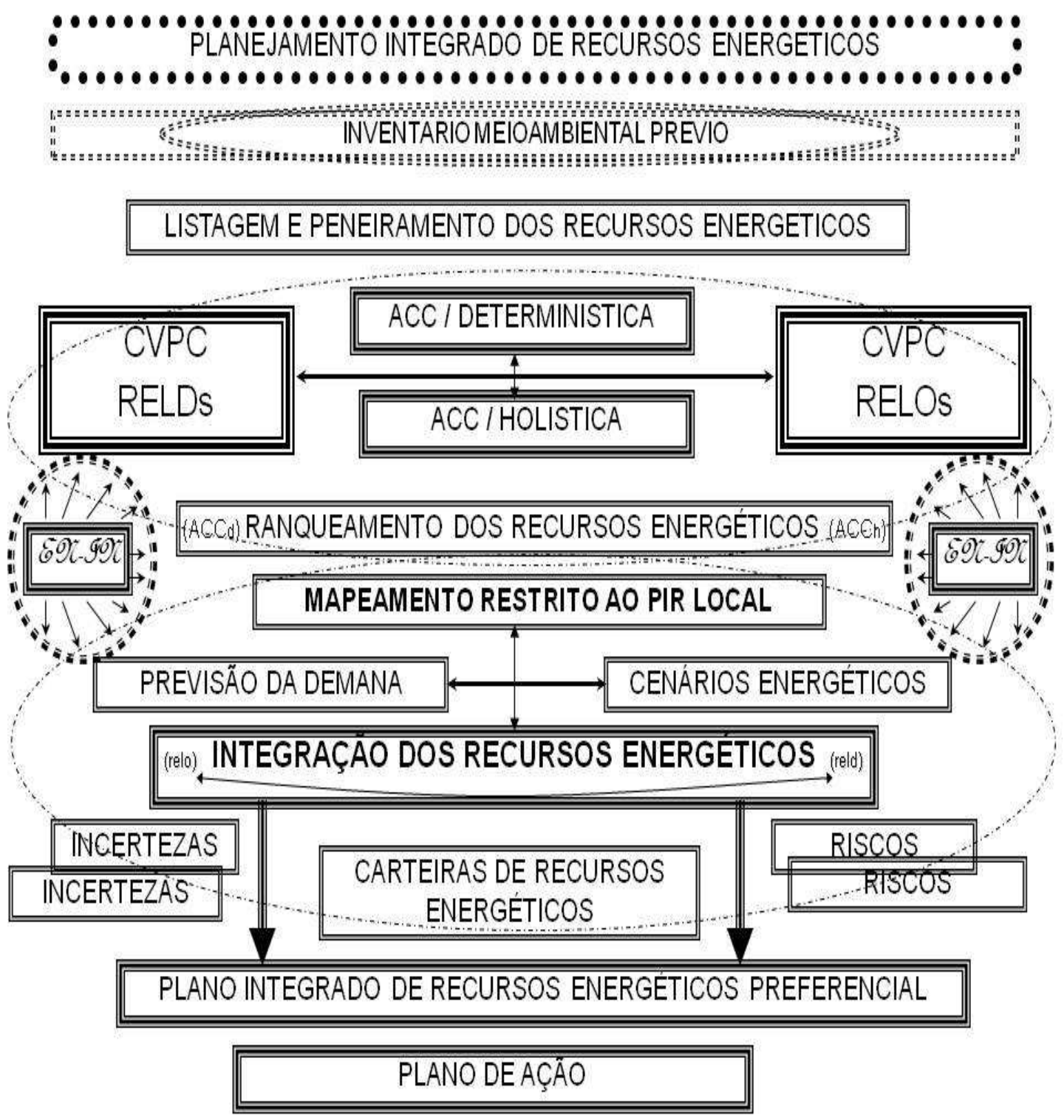

Figura 1: Modelagem Fundamental do Processo do PIRnaUSP.

Para facilitar a compreensão no caso da especificidade para RAA (PIR da RAA), pode-se dizer que o PIR conta com quatro grandes fases distintas e cronologicamente sequenciais, em que cada uma delas pode ser subdividida em etapas que podem ocorrer paralelamente ou não. São estas: 
- Informações Prévias: são obtidas informações que contribuirão para a construção das etapas ao longo da realização do PIR. Essa fase, quando já o PIR está em andamento após o plano de ação, vem a ser a reformulação periódica dos recursos energéticos (REs) com base no inventário ambiental prévio;

- Construção do Ranqueamento: o Ranqueamento em si é uma das etapas do PIR, e essa segunda fase conta com a aplicação das ferramentas metodológicas que irão levar à classificação dos recursos, com a aplicação da ACC (Avaliação dos Custos Completos), em um ranking decrescente de ordem de aproveitamento energético; porém, segundo a consideração multidimensional de atributos distintos das quatro dimensões consideradas na ACC do PIR para a Integração de Recursos;

- Plano Integrado de Recursos Energéticos Preferencial: é a integração em si. Engloba as fases anteriores aos elementos da metodologia de Integração de Recursos, fazendo uso do mapeamento energoambiental e dos vigilantes identificados numa geografia e num tempo específicos;

- Plano de Ação: etapa final, traz à luz dos En-In os resultados obtidos. No caso de um PIR sob responsabilidade de um dado tomador de decisão, esse plano de ação (normalmente o responsável pela execução do PIR) comporta os recursos energéticos que devem ser implementados de imediato, dando início ao processo do PIR, visando o desenvolvimento sustentável.

A Figura 2 (BERNAL, 2009) apresenta o modelo esquemático do Planejamento Integrado de Recursos energéticos como atualmente é dominado pela equipe de PIRnaUSP, após consolidação multiobjetiva e multicritério das etapas realizadas, comprometidas pelo projeto de pesquisa. 


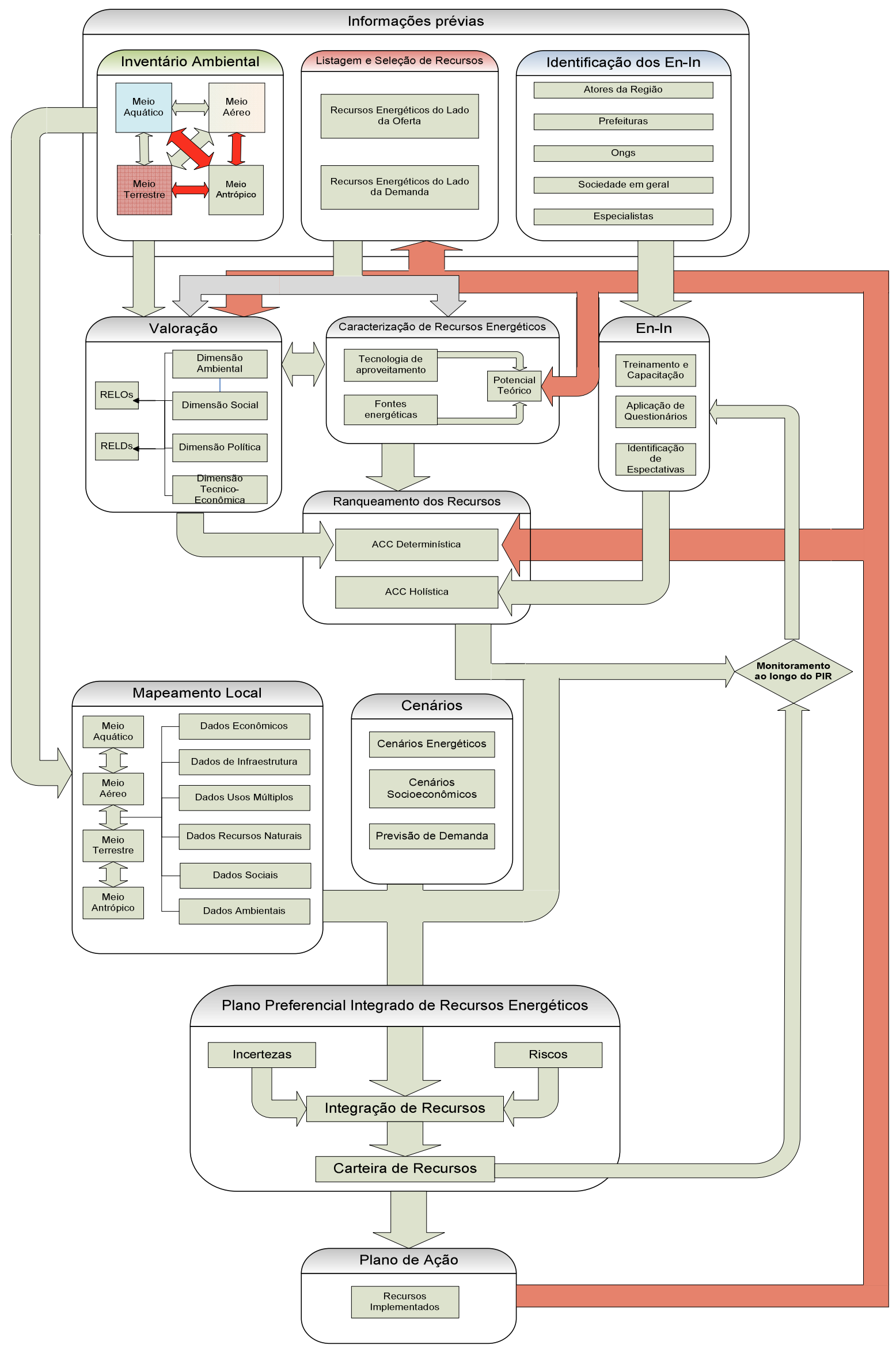

Figura 2: Diagrama Esquemático do Planejamento Integrado de Recursos energéticos. 


\section{Realizações de Consolidação do PIRnaUSP}

\subsection{Introdução}

O processo de consolidação e verificação das partes (modelagem, metodologia, procedimentos, ferramentas modulares) da tese do PIRnaUSP se realiza sinergicamente ao longo de duas etapas. Assim sendo, ao longo do primeiro ano do desenvolvimento da pesquisa científica de engenharia, enfatizou-se o processo de diagnóstico da região com os procedimentos de:

- Pesquisa de campo e levantamento de dados para a composição da caracterização da região, georreferenciamento de pontos de interesse para a pesquisa;

- Construção da estrutura da Mina de Dados e inclusão dos dados coletados;

- Composição do Inventário Ambiental Prévio;

- Capacitação da equipe da entidade parceira e discussão com os En-In, no intuito de realizar treinamentos técnicos, ciclos de palestras, dinâmicas de ACC e treinamentos voltados ao software Decision Lens;

- Levantamento prévio dos REs da RAA.

Nesse sentido, os trabalhos do PIRnaUSP, como já afirmado, desenvolvem-se concomitantemente às atividades realizadas no PIR da RAA (ao qual se amarra o projeto FAPESP anteriormente mencionado). Sendo assim, na segunda etapa, buscou-se o aprimoramento do Inventário Ambiental, complementado com as informações colhidas e renovadas para a construção do Cômputo e Valoração do Potencial Completo (CVPC) dos Recursos Energéticos, com os seguintes trabalhos de pesquisa realizados: 
- Finalização do Inventário Ambiental Prévio;

- Alimentação e realimentação da Mina de Dados (enfoque na validação de fontes e referências, e renovação de dados já existentes);

- Finalização da capacitação da equipe parceira com a aplicação das dinâmicas de ACC em todas as dimensões de análise do PIR: ambiental, social, política e técnico-econômica, realizadas nesta ordem;

- Início da coleta de dados meteorológicos para levantamento dos potenciais eólico e solar da região;

- Caracterização georreferenciada completa da região;

- Realização de Avaliação de Custos Completos nas dimensões de análise do PIR, visando o Ranqueamento dos recursos energéticos.

Na terceira etapa dos trabalhos de pesquisa, foram realizadas atividades como:

- Ranqueamento dos recursos energéticos;

- Construção de cenários energéticos;

- Previsão da demanda para a RAA no horizonte de 30 anos;

- Definição da metodologia de integração de recursos;

- Levantamento dos potenciais teóricos completos dos recursos energéticos.

Os itens foram aqui descritos de forma a apenas listá-los e não poluir a compreensão abrangente que se pretende neste trabalho. O conteúdo completo encontra-se disponível no endereço: <http://seeds.usp.br/fapesp/03064417>. Os links correspondem ao número do arquivo anexo, que será numerado em suas respectivas referências segundo o aparecimento e a necessidade ao longo deste manuscrito. 


\subsection{Inventário Ambiental (energético) Prévio}

Um dos pilares fundamentais da metodologia de Planejamento Integrado de Recursos energéticos proposta é a incorporação, dentre outros, dos aspectos que tangem o aproveitamento de recursos energéticos: o ambiental, o social e o político. A adição de variáveis dessa natureza na análise de alternativas, para além do domínio técnico-econômico tradicionalmente considerado no planejamento energético, demanda a descrição mais acurada o quanto possível do que se definiu, no âmbito dos trabalhos do PIRnaUSP, como meio ambiente - domínios biofísicos do solo, água e atmosfera e domínio antrópico.

O Inventário (Energo)ambiental ${ }^{1}$ prévio serve de base inicial de dados que caracterizam a área de estudo do projeto, no caso, a RAA - Região Administrativa de Araçatuba - nestes termos. Para sua composição, formalmente, dever-se-ia medir a partir das grandezas físicas dos sistemas naturais e humanos. Porém, como ainda não se conta com essa instrumentação, em geral são empregados dados secundários de fontes diversas, tais quais relatórios de órgãos da administração direta e indireta do Estado de São Paulo, IBGE e outros estudos.

Essas informações servem de suporte para a definição das aptidões regionais de geração de energia, para que seja possível aperfeiçoar a matriz energética levando em conta as características na dimensão técnico-econômica e os desdobramentos nas dimensões ambientais, sociais e políticas do uso dos recursos energéticos disponíveis. Além disso, o Inventário Energoambiental prévio (ou Inventário Ambiental pró-energético) é a fonte de

\footnotetext{
${ }^{1}$ No jargão do PIRnaUSP, deve ser conhecido como inventário energoambiental, para se diferenciar do tradicional conceito do inventário ambiental orientado aos estudos de impactos ambientais de Lei. Isso fundamentalmente porque se trata de descrever o estado de coisas nos quatro meios (antrópico, terrestre, aéreo e aquático), horizontalmente e verticalmente (tanto no tempo como na geografia), visando essencialmente completar a etapas de peneiramento de recursos energéticos e do mapeamento energoambiental do PIRnaUSP.
} 
informações que respalda a determinação da capacidade de suporte da região, que, segundo os princípios do Planejamento Integrado de Recursos energéticos (PIR), deve-se pôr em evidência para que se estabeleça uma via evidente para o desenvolvimento sustentável.

O Inventário Ambiental (Energoambiental) prévio conta com dados sistematizados, tais como:

\section{Meio Antrópico}

- Histórico da região

- Aspectos demográficos

- Indicadores sociais

- Economia

- Infraestrutura

- Aspectos políticos

\section{Meio Aquático}

- Águas superficiais

- Avaliação de águas subterrâneas

- Demanda de água por UGHRI

- Balanço demanda versus disponibilidade

\section{Meio Terrestre}

- Geologia 
- Erosão

- Vegetação natural remanescente

- Biodiversidade

- Geomorfologia

- Gestão de resíduos sólidos urbanos

\section{Meio Aéreo}

- Emissões regionais

- Bacia aérea

- Materiais particulados

- Sistema de ventos

- Precipitações pluviais

\subsubsection{Tese de Doutorado}

O desenvolvimento do tópico de Inventário Energoambiental gerou a tese de doutorado:

KANAYAMA, P. H. Mecanismos de desenvolvimento limpo no planejamento integrado de recursos energéticos. 2007. Tese (Doutorado em Engenharia) - Escola Politécnica da USP, Universidade de São Paulo, São Paulo, 2007.

A referida tese está disponível em: <http://seeds.usp.br/portal/uploads/8f6b04ca-f8c218b7.pdf>. 
Resumo - O objetivo fundamental deste trabalho é introduzir efetivamente as variáveis do aquecimento global dentro do planejamento energético através do Planejamento Integrado de Recursos Energéticos - PIR. A causa do aquecimento que ameaça a vida como conhecemos na Terra não é a liberação de gases de efeito estufa por atividades antropogênicas. A liberação desenfreada dos gases de efeito estufa é uma consequência do modelo de desenvolvimento econômico, que incentiva o uso insustentável de energia e recursos naturais.

É necessário repensarmos o modelo de desenvolvimento, a causa do problema. Neste sentido, este trabalho apresenta uma alternativa de planejamento energético, que inclusive engloba a questão do aquecimento global.

Metodologicamente busca-se a satisfação das necessidades regionais para depois delinear as necessidades de uma macrorregião. A utilização dos recursos energéticos próprios da região é priorizada. A vocação econômica regional é vista como vantagem competitiva para melhoria de índices sociais. As limitações ambientais, incluindo os efeitos do aquecimento global, são consideradas. As forças políticas são respeitadas. Os atores envolvidos e interessados no desenvolvimento regional participam do planejamento. E o mais importante, a abordagem sistêmica para buscar o ótimo é feita antecipadamente, conseguindose prever consequências do desenvolvimento antes da implantação de projetos. Estes, com ganhos econômicos, sociais, ambientais e políticos, ao mesmo tempo, são priorizados em relação àqueles com ganhos predominantemente econômicos.

Dessa forma, minimizam-se riscos e dificuldades de licenciamentos ambientais, rejeição pública, bem como problemas decorrentes da utilização insustentável de recursos naturais. 
Para validar este trabalho, a metodologia é aplicada em uma região do interior do Estado de São Paulo, a Região Administrativa de Araçatuba, composta de um conjunto de 43 municípios.

$\mathrm{Na}$ conclusão, o trabalho aponta quais são os recursos energéticos que melhor se ajustam às premissas do desenvolvimento sustentável, que inclui a questão do aquecimento global.

O relatório técnico-científico sobre o Inventário Ambiental se encontra no link:

$<$ http://seeds.usp.br/fapesp/03064417/rtcpirnausp402.pdf $>$.

\subsection{Listagem, Peneiramento e Seleção dos Recursos Energéticos}

O PIR tem como uma de suas premissas básicas não descartar nenhum recurso energético a priori. Um recurso que não se apresente disponível ou não seja de interesse imediato pode ser incluído, por exemplo, cinco ou dez anos à frente, pois o PIR é um processo que se define no planejamento energético de longo prazo (que deve incluir cenários que incorporem efeitos no estilo de vida da sociedade), com tempos que devem ir além dos 30 anos na sua parte relativa ao longo prazo.

A listagem dos recursos energéticos visa identificar todos os recursos energéticos passíveis de uso ao longo do horizonte de planejamento, independente de características tecnológicas ou sua aceitação, seja social ou mercadológica.

Essa listagem engloba os RELOs que são caracterizados pelo duo (ou binômio) fonte energética/tecnologia de aproveitamento e RELDs, caracterizados pelo escalonamento de informações sobre o setor de aplicação, medida de GLD e o uso final. Esses dois tipos genéricos de recursos energéticos podem parecer distintos no planejamento tradicional, mas no PIR, ou mais especificamente no PIRnaUSP, são avaliados e classificados da mesma 
forma, sendo considerados de forma integrada e indissociável ao planejamento de longo prazo.

O peneiramento simplesmente é o momento prévio à seleção e ao Ranqueamento, no qual se suspende a consideração para a valoração completa de alguns recursos como determina as metodologias e procedimentos dentro da filosofia do PIR.

No caso do PIR da RAA (desenvolvido no contexto deste projeto), houve ainda a diferenciação dos RELOs, principalmente em faixas de potência de aplicação, que tem como objetivo auxiliar a listagem das tecnologias disponíveis para a fonte em determinadas faixas de potência e assim facilitar a determinação dos potenciais teóricos de cada um dos recursos.

Os RELOs nascem da combinação da faixa de potência com a fonte energética, listadas abaixo, que posteriormente, como parte do procedimento modular do PIR, quando do cômputo e valoração do potencial completo, são caracterizadas em tecnologias de aproveitamento.

Faixas de potência consideradas (tecnologia):

- Menores que $1 \mathrm{KW}$

- Entre $1 \mathrm{KW}$ e $10 \mathrm{KW}$

- Entre $10 \mathrm{KW}$ e $100 \mathrm{KW}$

- Entre $100 \mathrm{KW}$ e $500 \mathrm{KW}$

- Entre 500KW e $2 \mathrm{MW}$

- Entre 2MW e 30MW

- Entre 30MW e 200MW

- Maiores que 200MW 
Fontes energéticas listadas (fonte):

- Energia Solar

- Energia Eólica

- Energia Hidráulica

- Queima Direta

- Biocombustíveis

- Derivados de Petróleo

- Gás Natural

- Carvão

- Nuclear

Para os RELDs, segue abaixo a lista de setores, medidas de GLD e usos finais que caracterizam o recurso.

\section{Setores:}

- Comercial

- Industrial

- Residencial

\section{Medidas:}

- Controle de Carga

- Substituição, Ajuste e Dimensionamento de Equipamentos

- Seleção e Substituição de Energéticos e Eficientização de Sistemas de Combustão

- Projeto de Edificações Eficientes 
- Armazenamento de Energia

- Tarifação e Regulação

- Programas de Informação, Educação e Capacitação

\section{Usos Finais:}

- Iluminação

- Refrigeração

- Condicionamento Ambiental

- Aquecimento de Água

- Força Motriz Estacionária

- Fornos, Caldeiras e Fogões

\subsubsection{Dissertações de Mestrado}

A listagem e o peneiramento dos RELOs constam em:

FUJII, R. J. Modelo de caracterização sistêmica das opções de oferta energética para o PIR. 2006. Tese (Doutorado em Engenharia) - Escola Politécnica da USP, Universidade de São Paulo, São Paulo, 2006.

Disponível em: <http://www.teses.usp.br/teses/disponiveis/3/3143/tde-23042007$\underline{141058>}$, gerada a partir do desenvolvimento dos trabalhos do projeto.

Resumo - O planejamento energético tradicional geralmente privilegia os custos econômicos dos recursos energéticos, relegando ao segundo plano as questões políticas, sociais e ambientais. Este trabalho pretende estimular a mudança dessa abordagem através da proposição de um modelo de caracterização de recursos energéticos integrando todas essas 
quatro dimensões. São dois seus objetivos: o fornecimento de uma metodologia para avaliar o custo global dos recursos energéticos e de outra para estimar o potencial de tais recursos. Para facilitar o processo de avaliação, o modelo sugere o uso da ACC - Avaliação de Custos Completos, a qual permite a análise qualitativa e quantitativa de custos, reduzindo a necessidade de dados quantitativos, limitados em certos casos. Ilustra-se a aplicação do modelo com um exemplo de caracterização dos recursos na região de Araçatuba, localizada no Oeste Paulista. Os resultados revelam que, quando considerados os custos globais, a adoção de recursos renováveis apresenta grande competitividade, ao contrário de outros que, apesar de serem economicamente atraentes, não apresentam custos globais aceitáveis.

Já para os RELDs, consta em:

BAITELO, R. L. Modelagem completa e análise dos recursos energéticos do lado da demanda para o PIR. 2006. Dissertação (Mestrado em Engenharia) - Escola Politécnica da USP. Universidade de São Paulo, São Paulo, 2006.

Disponível em: <http://www.teses.usp.br/teses/disponiveis/3/3143/tde-08122006145602>, gerada a partir do desenvolvimento dos trabalhos do projeto.

Resumo - Esta dissertação propõe um modelo de caracterização de recursos energéticos do lado da demanda que pretende abranger todos os tipos de ações e medidas referentes ao gerenciamento da demanda e à conservação energética, avaliando-as de forma holística, dentro de quatro dimensões: técnico-econômica, ambiental, social e política. Os recursos considerados na composição do modelo são submetidos às fases de Inventário de Recursos Energéticos do Lado da Demanda, Caracterização das Dimensões e Atributos de Avaliação de Recursos, Formulação dos Potenciais Energéticos e Aplicação do Modelo em Caso Piloto. O Inventário de Recursos Energéticos do Lado da Demanda pretende levantar, 
descrever e segmentar todas as alternativas energéticas de GLD e setores de consumo energético. A Caracterização da Avaliação de Recursos delimita as esferas de análise de recursos e a caracterização de seus atributos quanto a custos e benefícios provenientes de seu emprego. A Formulação dos Potenciais Energéticos define seu cálculo a partir de sua amplitude e restrições gerais de aplicação. O modelo é aplicado em um estudo piloto, na Região Administrativa de Araçatuba, por meio de um exercício de formulação do PIR, considerando a utilização de ferramentas de Avaliação dos Custos Completos, Cálculo de Potenciais Energéticos e Elaboração de Cenários de Projeção do Consumo Energético para um horizonte de tempo determinado.

\subsection{Ferramentas de Suporte ao PIR (PIRnaUSP)}

Algumas ferramentas utilizadas para a construção do Planejamento Integrado de Recursos não são propriamente intrínsecas ao processo, porém são de imprescindível suporte para diversas etapas (muitas vezes presente em todas elas). Exemplos disso é a Mina de Dados, que consiste em um banco de dados consolidado com todas as informações passíveis de uso ou não que se possa recolher em uma única base para a RAA; ou o Georreferenciamento, que busca colocar em bases geográficas as informações contidas na Mina de Dados, no levantamento de potenciais e no Inventário Ambiental Prévio; ou ainda a ACC (Avaliação dos Custos Completos) para Ranqueamento essencial na integração dos recursos.

Os relatórios técnico-científicos sobre as ferramentas de suporte ao PIR se encontram nos links:

<http://seeds.usp.br/fapesp/03064417/rtcpirnausp403.pdf>;

<http://seeds.usp.br/fapesp/03064417/rtcpirnausp413.pdf $>$; 
<http://seeds.usp.br/fapesp/03064417/rtcpirnausp414.pdf>;

<http://seeds.usp.br/fapesp/03064417/rtcpirnausp415.pdf>;

<http://seeds.usp.br/fapesp/03064417/rtcpirnausp416.pdf>;

<http://seeds.usp.br/fapesp/03064417/rtcpirnausp417.pdf $>$;

〈http://seeds.usp.br/fapesp/03064417/rtcpirnausp418.pdf>;

< $\underline{\text { http://seeds.usp.br/fapesp/03064417/rtcpirnausp419.pdf>; }}$

〈http://seeds.usp.br/fapesp/03064417/rtcpirnausp420.pdf>;

$<$ http://seeds.usp.br/fapesp/03064417/rtcpirnausp421.pdf $>$;

<http://seeds.usp.br/fapesp/03064417/rtcpirnausp422.pdf>;

<http://seeds.usp.br/fapesp/03064417/rtcpirnausp423.pdf>.

\subsubsection{Tese de Doutorado em Andamento}

A ferramenta de georreferenciamento está sendo trabalhada na tese de doutorado:

AZEVEDO, F. M. Modelagem e implementação de um sistema de análise geoenergética sob a visão do planejamento integrado de recursos - PIR. IEE/USP.

\subsection{Envolvidos e Interessados (En-In)}

A metodologia de PIR se difere do planejamento em diversos aspectos relevantes ao desenvolvimento sustentável. Um deles é a introdução da participação de todos os atores, relevantes ao planejamento, sejam eles organizações não governamentais, poder público, 
interessados locais, especialistas de diferentes áreas do conhecimento e a sociedade organizada em geral.

O envolvimento dos En-In deu-se de forma qualificada com a participação em oficinas de treinamento e dinâmicas de grupo, em que foram apresentados os recursos energéticos pela perspectiva de cada uma das dimensões de análise do PIR: social, ambiental, política e técnico-econômica.

Alguns dos En-In identificados, no caso especifico do PIR da RAA, são:

- prefeituras dos municípios da RAA;

- Cooperhidro

- Nestlé

- Clealco

- Aralco

- Bertin

- Klin

- Equipav

- Transen e outras empresas

- UniSalesiano

- Aeroporto Dário Guarita

- Sociedade organizada em geral 


\subsection{Caracterização de Recursos Energéticos}

Os diagnósticos de oferta e de demanda energéticas, acompanhado de uma consolidação do potencial não utilizado dos recursos energéticos da região, buscam preencher a lista de recursos formados pelo duo fonte/tecnologia de aproveitamento, com a característica dos potenciais teóricos, que se referem ao máximo aproveitamento considerando os limites do recurso, e aos potenciais realizáveis, referentes à intersecção dos limites impostos por cada uma das dimensões de análise do PIR: ambiental, social, política e técnico-econômica.

\subsubsection{Recursos Energéticos do Lado da Oferta - RELO}

A caracterização dos RELOs vem consolidar uma base de dados com informações referentes a diversas fontes energéticas do Lado da Oferta de energia, bem como de seus geradores e suas características. Ao serem caracterizados e calculados os potenciais de oferta da região com suas limitações e influências do mercado atual, levam-se em conta aspectos não somente técnicos e econômicos, mas também o efeito causado pela sua utilização no meio ambiente, a influência da política local e seus efeitos na sociedade ao redor.

Foi realizado um levantamento das diversas tecnologias existentes atualmente para a produção de energia, através de variadas fontes, sejam elas renováveis ou não. Nestas, para a RAA, foram avaliados:

- Potencial teórico

- Potencial realizável

- Potencial de mercado

Dessa forma, obtém-se uma ferramenta eficiente para auxiliar no PIR, considerando conjuntamente características antes tratadas de forma individual. 
A caracterização do potencial teórico de oferta de energia envolve todas as possíveis tecnologias para a produção de energia elétrica ou para o aproveitamento dos recursos existentes na região em estudo. Tais tecnologias podem ser utilizadas para o aproveitamento das fontes hídricas, solares, de biomassa, nucleares, geotérmicas, a gás natural, dentre outras. Isso possibilita analisar cada um dos recursos de forma completa, englobando suas características construtivas e os atributos de, pelo menos, seu sistema de geração de energia mais apropriado, considerando fatores como eficiência, custos, influência no meio ambiente e benefícios, tanto para o mercado nacional quanto para o internacional.

A caracterização dos RELOs também consta em Fujii (2006) citado no item 4.3.1.

\subsubsection{Recursos Energéticos do Lado da Demanda - RELD}

Dentro do atual contexto do ciclo dos programas de eficiência energética propostos pelas concessionárias de distribuição que operam no país, percebe-se que os projetos voltados para a redução do desperdício no consumo de energia elétrica têm recebido certa prioridade. Esse fato é um forte indício para se incorporar, afetando a previsão do mercado de energia no escopo do planejamento tal redução. Esses projetos devem ser avaliados na composição das carteiras dos recursos do lado da demanda, demonstrando assim que os RELDs não são uma novidade, mas sim o seu manuseio no processo do Planejamento Integrado dos Recursos energéticos.

Com o intuito de avaliar esse potencial e incluí-lo na carteira dos recursos energéticos, faz-se a caracterização de todas as tecnologias dos usos finais de possível utilização, a caracterização dos recursos do lado da demanda para que possam ser avaliados os potenciais teórico, realizável e de mercado na região. Para essa caracterização, utilizou-se a metodologia 
da modelagem dos recursos do lado da demanda (BAITELO, 2006). Após a caracterização das tecnologias e dos recursos são feitos os cálculos dos potenciais teóricos

As tecnologias e os recursos considerados nessa caracterização são submetidos às fases de Inventário de Recursos Energéticos do Lado da Demanda, Caracterização das Quatro Dimensões do PIR (técnico-econômica, ambiental, social e política), Atributos de Avaliação de Recursos e Formulação dos Potenciais Energéticos. Para tanto, foram levantadas e caracterizadas as tecnologias e os recursos energéticos do Lado da Demanda, descrevendo todos os aspectos técnicos de cada tecnologia, dos seus atributos, bem como delimitando e formulando a metodologia utilizada para essa caracterização e cálculos dos potenciais teóricos (porém realizável).

A definição dos procedimentos para a caracterização das tecnologias e dos Recursos Energéticos do Lado da Demanda deve explicitar uma metodologia de levantamento, caracterização e análise de todas as alternativas energéticas do lado da demanda, representadas pelos usos finais (em relação sinérgica às medidas e setores de consumo). Esses recursos considerados na composição do modelo foram submetidos às seguintes fases:

- Caracterização de Tecnologias de Usos Finais: através do levantamento das tecnologias junto a fabricantes, importadoras, fornecedores, indústrias locais, comércio local, agroindústria, pesca, serviços públicos da região etc.

- Caracterização de RELD: através do levantamento e da descrição de todas as alternativas energéticas e sua segmentação em diferentes grupos de medidas e ações, usos finais e tecnologias associadas de GLD e setores de consumo energético;

- Caracterização das Quatro Dimensões de Avaliação de Recursos: delimitação das esferas técnico-econômica, ambiental, social e política de análise de recursos e a caracterização de seus atributos e subatributos (representando impactos inerentes à 
utilização e implantação de recursos), visando uma avaliação completa dos RELDs quanto a custos e benefícios provenientes de seu emprego;

- Estimativa dos Potenciais Energéticos Teórico, Realizável e de Mercado: caracterização dos potenciais energéticos teórico, realizável e de mercado quanto a sua amplitude e suas restrições de aplicação delimitadas nas quatro dimensões de análise e particularizadas para cada recurso analisado.

Para atingir os objetivos acima descritos, foi elaborada uma metodologia que orientasse de forma clara sobre os procedimentos a adotar na caracterização de tecnologias e de recursos do lado de demanda.

A metodologia adotada para a caracterização de tecnologias dos recursos do lado da demanda conta com outras fases (inerentes ao PIR), tais como:

- Delimitação do local de estudo: entende-se pela delimitação da fronteira geográfica onde deve ocorrer o levantamento e a caracterização de tecnologias e de usos finais;

- Identificação das principais atividades econômicas do consumo de energia do local do estudo: na identificação das principais atividades econômicas, devem-se levantar as características destas por setor industrial, comercial, residencial, público, agropecuário (rural);

- Estratificação dos usos finais dos setores e subsetores;

- Levantamento das tecnologias dos usos finais locais e do mercado (nacional e internacional) e suas características técnico-econômicas, ambientais, sociais, políticas;

- Estimativa dos potenciais teórico, realizável e de mercado dos recursos levantados.

A caracterização dos RELDs também consta em Baitelo (2006), citado no item 4.3.1 


\subsubsection{Dissertação de Mestrado em Andamento}

O levantamento de potenciais energéticos e a aplicação da caracterização de RELDs para o PIR serão abordados na dissertação de mestrado em andamento: CARNEIRO, P. R. Caracterização de recursos energéticos e o PIR regional: Estudo de caso RAA/SP.

\subsection{Cômputo e Valoração do Potencial Completo (CVPC)}

O processo de Cômputo e Valoração do Potencial Completo (CVPC) dos recursos energéticos, isto é, o CVPC dos RELO e o CVPC dos RELD, tem como objetivo a definição do potencial completo (quantitativo e/ou qualitativo) do recurso energético nas quatro dimensões consideradas na metodologia PIR, ou seja, o cômputo e a valoração do potencial completo da fonte junto com a tecnologia (no caso do RELO) e uso final junto com a medida e o setor (no caso do RELD) a ser utilizada para o seu desenvolvimento e aplicação.

Nesse contexto, para uma valoração dos recursos energéticos numa determinada região dentro do processo do PIR, necessariamente se deve começar com o levantamento dos recursos existentes na região, a sua caracterização e a avaliação dos potenciais teóricos (que no caso do PIRnaUSP, significa o potencial realizável teórico).

Após a obtenção do potencial teórico, parte-se para a valoração, com o intuito de obter o potencial realizável e estruturar a formação de carteiras de recursos e a integração destes ao longo do tempo. Uma vez visualizada a carteira de recursos através desse processo, pode-se elaborar concomitantemente o Plano Integrado de Recursos Preferencial, visando uma locação racional e eficiente dos recursos energéticos (indistintamente RELO e/ou RELD). 
Nesse processo de valoração, procede-se ao cômputo (via procedimento e/ou algoritmo predeterminado) de cada atributo e/ou subatributo, em cada uma das quatro dimensões (técnico-econômica, ambiental, social e política), definidos na etapa de caracterização de recursos energéticos. Além dos potenciais avaliados na etapa anterior, são considerados de forma efetiva todos os elementos (atributos), tais como os custos específicos das tecnologias envolvidas, taxas de juros praticadas no mercado, entre outros.

\subsubsection{Tese de Doutorado}

A sistematização metodológica do CVPC dos Recursos Energéticos faz parte da seguinte tese de doutorado:

BAITELO, R. L. Modelo de cômputo e valoração de potenciais completos de recursos energéticos para o planejamento integrado de recursos. 2011. Tese (Doutorado em Engenharia) - Escola Politécnica da USP. Universidade de São Paulo, São Paulo, 2011. Disponível em: <http://www.teses.usp.br/teses/disponiveis/3/3143/tde-01032011-142528/ptbr.php>.

Os relatórios técnico-científicos sobre o Cômputo e Valoração dos Potenciais Completos dos Recursos Energéticos da RAA se encontram nos links:

<http://seeds.usp.br/fapesp/03064417/rtcpirnausp404.pdf >;

<http://seeds.usp.br/fapesp/03064417/rtcpirnausp405.pdf>;

<http://seeds.usp.br/fapesp/03064417/rtcpirnausp406.pdf >;

<http://seeds.usp.br/fapesp/03064417/rtcpirnausp407.pdf>;

<http://seeds.usp.br/fapesp/03064417/rtcpirnausp408.pdf $>$. 


\subsection{Avaliação dos Custos Completos - ACC}

Dentro do PIR se faz necessária a classificação dos recursos energéticos segundo o seu menor ou maior custo completo, isto é, uma seleção multicritério com base nos diferentes atributos das dimensões, que determinam a valoração completa de um recurso no PIR. Isso inclui a comparação entre RELO e RELD, de forma que seja gerado um ranking de sugestão de recursos, que vai do mais indicado para o menos indicado. Porém, consideram-se todos os custos de forma simultânea e multiobjetiva, através das quatro dimensões já definidas (tendo o mesmo significado no CVPC e na ACC). É importante pôr em evidência que no caso do CVPC dos recursos energéticos o resultado é multidimensional y quali-quantitativo, dando uma visão matricial do potencial do recurso; já no caso da $\mathrm{ACC}$, o resultado é uma normalização dos atributos (por unidade) e classificação quantitativa final.

Usualmente, não há CVPC nem ACC e, essa tomada de decisão é realizada a partir de dados econômicos e técnicos. Porém, tendo em vista as muitas variáveis não técnicas que limitam a implantação de recursos energéticos, os impactos negativos e positivos da adoção dos recursos devem ser considerados de forma que o resultado global final reflita o maior número de aspectos possíveis (dentre eles, estão os ambientais, sociais e políticos). Mais do que isso, assumir as dimensões do desenvolvimento (técnico-econômica, ambiental, social e política), como custos que devem ser parametrizados e incorporados efetivamente na avaliação do recurso energético, ou seja, a filosofia do PIR aqui desenvolvida. As maiores dificuldades de se considerar esses tipos de impactos são a subjetividade e a precificação. Tais inconvenientes são mais pelo desconhecimento e o não uso de ferramentas mais completas, como a ACC e o CVPC, do que por incertezas em tais subjetividades assim assumidas no passado.

Tal precificação, também conhecida como internalização ou monetarização, é a maneira usual de se tratar aspectos subjetivos nas tomadas de decisões, pois através dela todos 
os aspectos tornam-se diretamente comparáveis. Por outro lado, o próprio método de precificação utiliza diversas premissas qualitativas, de modo que os valores quantitativos gerados podem ser diferentes para cada pessoa que fizer a precificação, dependendo das hipóteses assumidas. Por isso mesmo, a utilização da precificação deve ser muito bem pensada, e as hipóteses consideradas devem estar muito claras para aqueles que utilizarão essas informações.

Na base da sua formulação teórica (CARVALHO, 2000), existem três tipos de custos considerados na Avaliação de Custos Completos (ACC), os internos, os menos tangíveis ou ocultos e os externos.

Os custos internos são tradicionalmente contabilizados e pagos diretamente. São exemplos, os custos de instalação, manutenção, dos insumos, depreciações, impostos pagos e o custo de operação são exemplos de custos internos.

São considerados custos menos tangíveis, indiretos ou ocultos aqueles conhecidos, mas não incorporados na tomada de decisão. Como exemplos desse tipo de custos, podem ser citados os custos de limpeza de córregos, nos quais são despejados dejetos, o custo de obtenção de licenças etc.

Já os custos externos não são arcados por usuários ou empresa, mas impostos a outros elementos da sociedade. Por exemplo, o custo gerado pela alteração na atividade de pesca de uma comunidade ribeirinha, causado pela alteração de níveis de poluentes na água lançados por uma atividade industrial.

A ACC propõe-se como metodologia de cálculo dos custos completos de um empreendimento, isto é, a soma dos custos internos, dos menos tangíveis e externos. Caso não seja possível a precificação de um custo externo, a ACC ainda propõe sua consideração na forma holística. 
A utilização da ACC dentro do PIR é feita de duas formas distintas que convergem para um único ranking de recursos energéticos, sendo necessário que os atributos, subatributos e alternativas sejam idênticos para um posterior cruzamento de suas informações. É bom mencionar que isso tudo ratifica que cada PIR é um PIR sui generis.

A primeira utilização se dá na chamada ACC determinística, na qual é feita a normalização atributo por atributo, resultando em equivalência numérica para todos. Assim sendo, todas as notas atribuídas aos recursos energéticos são estimadas deterministicamente, independentemente se os valores atribuídos forem quantitativos ou qualitativos, fundamentalmente nas dimensões: ambiental, social e política. Esse tipo de utilização da ACC é complexo e pode ser ainda mais, pois todos os aspectos considerados devem ser valorados numericamente ou descrito segundo qualidades evidentes, seja na forma monetária ou em outra que se mostre útil. Daí então, as notas são normalizadas com valores por unidade para cada atributo, facilitando, enfim, seu manuseio numérico. Pode-se dizer que todas as externalidades devem ser internalizadas, de forma a serem consideradas indistinta, quantitativa e/ou qualitativamente, com base no CVPC dos recursos. Apesar da dificuldade de cálculo, para um PIR completo e rigoroso, deve-se contar com essas informações.

Ainda sobre a ACC determinística, para uma análise de sensibilidade no contexto das quatro dimensões consideradas (por ser da filosofia do PIR aqui trabalhada), os pesos dos subatributos podem ser levantados junto a especialistas. Para esse procedimento é utilizada a comparação par a par dentro do Processo Analítico Hierárquico (PAH) (CICONE JR., 2008).

A segunda utilização é realizada na ACC conduzida através dos En-In. Essa avaliação é totalmente holística, os subatributos são comparados entre si como na ACC determinística, porém com a opção de todos os En-In e os recursos a serem avaliados com relação aos subatributos. Essa avaliação é feita utilizando meios diversos, inclusive de uma escala verbal, 
que também está inserida dentro da metodologia de tomada de decisão do PAH (REINIG, 2008).

Cabe ressaltar que no contexto do que estamos aqui chamando de PIRnaUSP e, neste momento em que se tem finalizado todas as etapas de execução dos trabalhos do projeto PIR da RAA, todo o processo da ACC no PIRnaUSP que engloba valoração, oficinas e treinamento tem por denominação "Ranqueamento".

\subsubsection{Dissertação de Mestrado}

A análise da ACC como aplicação metodológica dentro do PIRnaUSP e, portanto do PIR da RAA, gerou a seguinte dissertação:

CICONE, D. J. Modelagem e aplicação da avaliação de custos completos através do processo analítico hierárquico dentro do planejamento integrado de recursos. 2008. Dissertação (Mestrado em Engenharia) - Escola Politécnica da USP. Universidade de São Paulo, São Paulo, 2008.

Disponível em: 〈http://www.teses.usp.br/teses/disponiveis/3/3143/tde-08062009-164421>.

Resumo - A proposta deste trabalho é apresentar o Processo Analítico Hierárquico e demonstrar que sua utilização é válida para a construção da Avaliação de Custos Completos. Assim como, apresentar o programa Decision Lens que implementa tal teoria. Outro objetivo desta dissertação é desenvolver e aplicar um método de Avaliação de Custos Completos estimado pelos Envolvidos-Interessados, chegando-se até o ranking de recursos energéticos e comparando-o com o ranking da valoração determinística. Para se justificar a validade e viabilidade do Processo Analítico Hierárquico dentro da Avaliação de Custos Completos, explica-se a teoria que o embasa. É desenvolvido um exemplo em que todos os cálculos são feitos manualmente, até chegar ao ranking de recursos energéticos finais. O mesmo exercício 
é desenvolvido no programa Decision Lens, comparando-se, assim, o resultado do exemplo manual com o exemplo desenvolvido no programa e validando-o. Para o desenvolvimento e aplicação de um método de Avaliação de Custos Completos valorado pelos EnvolvidosInteressados são realizadas atividades dentro do projeto Fapesp PIR Araçatuba. O processo de construção da árvore de decisão, com os subatributos e recursos energéticos considerados e de obtenção de dados da região piloto, são conduzidos no decorrer deste trabalho. A inserção desses dados no programa, bem como a apresentação dos resultados com análise de sensibilidade, são feitas e discutidas. Também é conduzida a confecção da tabela de valores e de seus ratings para a Avaliação de Custos Completos, estimada deterministicamente, com a inserção dos dados e com a apresentação dos resultados. Por fim, é realizada a comparação do resultado das duas Avaliações de Custos Completos, comentando-se as diferenças e similaridades existentes, mostrando que o resultado de uma é compatível com o resultado da outra.

\subsubsection{Ranqueamento de Recursos Energéticos}

O Ranqueamento gerado tanto na ACC determinística quanto na ACC holística são parâmetros utilizados no processo de integração de recursos energéticos e na construção das carteiras de recursos. O Ranqueamento é a seleção de recursos validada pelo processo ACC, e a carteira, uma sugestão embasada ao tomador de decisão. Para tanto, leva-se em conta dados factuais, as escolhas da sociedade através dos En-In (Envolvidos-Interessados) e de especialistas.

Nenhum recurso deve ser descartado devido a sua classificação no ranking, pois dentro do PIR ainda são consideradas variáveis temporais, geográficas e a disponibilidade do 
recurso, podendo ser bom daqui a algum tempo um recurso que no início do horizonte de planejamento se encontrava em posições inferiores no ranking de recursos energéticos.

A ACC holística é realizada com a aplicação de avaliações dirigidas, normalmente em sinergia com oficinas de PIR, realizadas durante os trabalhos de aplicação dos procedimentos, metodologias e modelos inerentes ao PIRnaUSP. No caso do PIR da RAA, a ACC holística foi aplicada imediatamente após os treinamentos e dinâmicas dentro do ciclo de palestras na região. Já a ACC quantitativa, bem como o ranking dos recursos energéticos, foram desenvolvidos e apresentados em Cicone (2008) e Reinig (2008).

\subsubsection{Tese de Doutorado em Andamento}

Os recursos energéticos e sua análise serão expandidos na seguinte tese de doutorado, com previsão de defesa para fevereiro de 2013:

RIGOLIN, P. H. C. Análise e desenvolvimento de um sistema para classificar (ranquear) RELOs e RELDs com base no cômputo e na valoração do potencial completo dos recursos energéticos dentro do PIR. Escola Politécnica, Universidade de São Paulo, São Paulo.

\subsubsection{Trabalho Final de Graduação}

O Ranqueamento dos recursos energéticos através da aplicação da ACC foi descrito dentro do trabalho de graduação:

REINIG, A. O. Aplicação da análise de custos completos no PIR visando o gás-natural e outros energéticos não renováveis para a região administrativa de Araçatuba. 2008. Trabalho de Conclusão de Curso. (Graduação em Engenharia) - Escola Politécnica da USP. Universidade de São Paulo, São Paulo, 2008. 
Resumo - A proposta deste trabalho visa a validação da aplicação da metodologia de Análise de Custos Completos (ACC), em conjunto com a implementação do Processo de Análise Hierárquica (PAH), para tomada de decisão a respeito das melhores opções de recursos energéticos (RE), buscando o desenvolvimento sustentável, dentro do Planejamento Integrado de Recursos (PIR), para a Região Administrativa de Araçatuba (RAA). Com base nos resultados, pretende-se avaliar a viabilidade da utilização de gás natural e outros combustíveis fósseis, como fontes energéticas frente a outras fontes para a composição de carteiras de recursos energéticos específicas. Para a escolha das melhores opções foram utilizados dois tipos principais de Ranqueamento, envolvendo RE de demanda e de oferta conjuntamente, o determinístico e o qualitativo que juntos formam o Ranqueamento geral; sendo o qualitativo formado por dois subtipos, o dos especialistas e o dos En-In. Desta maneira, foram obtidos os RE Coletores Solares e Medidas de Informação e Educação como os recursos prioritários tanto no Ranqueamento determinístico, quanto no qualitativo e no geral. Já o gás natural aparece pela primeira vez (Gás Natural para Cogeração) em décimo quinto, décimo sexto e décimo sétimo, respectivamente. Os resultados tornaram possível validar a proposta e também permitiu observar a prioridade do Gás Natural e outros recursos fósseis para compor carteiras de RE em possíveis cenários, demonstrando que este será o primeiro combustível fóssil a entrar na composição das carteiras analisadas.

O relatório técnico-científico sobre o Ranqueamento dos Recursos Energéticos da RAA se encontra no link: 〈http://seeds.usp.br/fapesp/03064417/rtcpirnausp424.pdf>.

\subsection{Mapeamento Regional Pró-Energético}

O mapeamento regional (denominado mapeamento energoambiental dentro do PIRnaUSP) vem a ser de fundamental importância no processo da integração de recursos, 
uma vez que é dele que se depreendem os dados e as características particulares da região de estudo, além de fornecer subsídios à etapa de participação dos Envolvidos-Interessados.

O mapeamento energoambiental local, ao ser um retrato do instante em que o recurso é posto para entrar satisfazendo a próxima necessidade de energia da RAA, permite a verificação se dito recurso vindo do Ranqueamento deverá esperar ainda o processo de integração de recursos energéticos (fase crucial do PIRnaUSP). Cabe esclarecer que o recurso é posto à espera (mesmo tendo uma posição ACC, no Ranqueamento, boa) sempre que algum indicador de impacto no meio ambiente dele extrapole as limitações determinadas por lei, já que o meio (meio aéreo, por exemplo) do indicador em questão poderia ficar saturado nesse indicador específico. Um exemplo simples de análise pode ser visto com a emissão de material particulado (MP).

No mapeamento (entenda-se mapeamento energoambiental no PIRnaUSP), assumindo o exemplo do MP já mencionado, esse indicador apresenta um valor dado nesse instante (trata-se do ano de análise no caso da integração de recursos no PIR da RAA), que representa uma folga de $20 \%$ com referência a determinado limite máximo (que no caso da RAA seria a Cetesb que determinaria). O próximo recurso do Ranqueamento a entrar definido na Integração de Recursos, nesse indicador específico, supera esses $20 \%$ de folga. Portanto, ficará à espera, tentando a cada momento da integração se a folga já foi ampliada, isto é, na composição do plano preferencial.

Para a construção do Mapeamento Regional as informações do inventário ambiental prévio são transformadas em parâmetros e índices que apresentam a região de forma estática, ou seja, tais parâmetros são uma descrição do momento em que foram analisados. Sempre respeitando a modelagem consolidada no PIR da RAA, como são os quatro meios que descrevem ou caracterizam exaustivamente a região (meio aéreo, meio terrestre, meio aquático e meio antrópico). 
O retrato momentâneo, da geografia relativa ao PIR (PIR da RAA no nosso caso de estudo), determinado no mapeamento energoambiental (uma fotografia para dar início ao processo de PIR regional) pretende, no caso do PIRnaUSP, constituir indicadores específicos de controle para o processo da integração dos recursos. Tais indicadores, denominados no jargão do PIRnaUSP de Vigilantes (RTC/PIRnaUSP $-\mathrm{n}^{\circ} 412$, 2009), foram definidos, no caso específico deste trabalho (PIR da RAA), como sendo:

- Meio aéreo

- O3 (atmosférico)

- MP

- VOHC* (medição de organovoláteis - CH4)

- GEE

- Meio aquático

- Disponibilidade hídrica

- $\mathrm{DBO}$

- $\mathrm{PH}$

- Meio terrestre

- Uso do solo

- Áreas impróprias

- IQR

- Meio antrópico

- Grau de urbanização 
- Crescimento populacional

- Vínculos empregatícios

- IDH

\subsubsection{Trabalhos Finais de Graduação}

O estudo do mapeamento energoambiental no processo do desenvolvimento da sua modelagem e verificação, como instrumento do PIRnaUSP, gerou os seguintes trabalhos de graduação:

1) COELhO, F. C. Avaliação da cadeia produtiva do biodiesel e seus efeitos na produção e mercado de alimentos através da metodologia PIR - Estudo de caso: região administrativa de Araçatuba. 2008. Trabalho de Conclusão de Curso (Graduação em Engenharia) - Escola Politécnica da USP. Universidade de São Paulo, São Paulo, 2008.

Disponível em: 〈http://seeds.usp.br/portal/uploads/TF_felipe_coelho.pdf>.

Resumo - O presente trabalho aborda e avalia a cadeia produtiva do biodiesel como um todo, como orienta o Planejamento Integrado de Recursos (PIR), o qual, diferentemente do planejamento tradicional, considera a disponibilidade geral de recursos, ranqueando-os de maneira a contemplar dimensões outras que a econômica - como a social, ambiental e política.

Abstrai-se aqui o sentido original do PIR, voltado à integração dos recursos para o planejamento do setor elétrico, já que é aplicado para o planejamento da introdução do biodiesel na matriz de combustíveis veiculares. Nesse sentido, adapta-se a metodologia da 
valoração completa do recurso, de forma a subsidiar a tomada de decisão quanto ao recurso energético, para a Região Administrativa de Araçatuba (RAA).

Cita-se como exemplo a valoração do biodiesel, na dimensão ambiental, no meio aéreo, critério "emissão de poluentes atmosféricos".

Evidencia-se, ao longo do trabalho, um desafio metodológico circunscrito na quantificação de alguns resultados. Na dimensão social, critério "aspectos estéticos", a valoração depara-se com a subjetividade inerente ao julgamento em questão. Este critério é abordado de forma qualitativa, a fim de validar a metodologia. São feitos comentários, quando necessário, que tentam induzir o processo à racionalidade necessária em projetos de planejamento energético. Deixa-se claro que o próximo passo da metodologia PIR é a comparação entre os diferentes recursos, o que demandará devida ponderação dos resultados obtidos.

A introdução da bioenergia na matriz energética pode causar polêmicas em torno da mudança do uso do solo agricultável, o qual historicamente é destinado à agricultura para o suprimento das necessidades energéticas humanas. Em face desse dilema e da fusão dos mercados energético e alimentício, o trabalho analisa a compatibilidade entre as produções de biodiesel e alimento, no que tange ao suprimento das necessidades regionais.

Os resultados demonstram a capacidade existente da região em produzir o biodiesel, na forma do B20, necessário para atender a demanda de óleo em 30 anos, sem desestabilizar, em termos de disponibilidade agrária, a produção de alimentos.

2) SADO, I. A. Comparação entre os desempenhos ambientais da gasolina e do etanol para a situação brasileira usando a técnica de avaliação de ciclo de vida. 2008. 
Trabalho de Conclusão de Curso (Graduação em Engenharia) - Escola Politécnica da USP. Universidade de São Paulo, São Paulo, 2008.

Resumo - O novo ciclo de expansão da indústria canavieira brasileira apresenta expectativas de crescimento tanto pelo mercado interno, representadas pelo apoio político e pelos motores bicombustíveis, quanto pelo mercado externo. O atendimento dessa vasta e ascendente demanda trouxe novas preocupações devido ao avanço das monoculturas e surgimento de diferentes impactos ambientais.

Frente a esse crescimento, surge uma nova discussão sobre os benefícios e malefícios da substituição da gasolina pelo etanol. Embora exerçam a mesma função, esses combustíveis são completamente diferentes com relação à forma como são obtidos e consequentemente em relação aos seus impactos ambientais.

Esse trabalho traz uma comparação da avaliação dos desempenhos ambientais do etanol e da gasolina para a situação brasileira, utilizando a análise de ciclo de vida como ferramenta. Essa análise, também conhecida como análise "do berço ao túmulo", pertence a uma classe de técnicas da gestão ambiental que visa avaliar o desempenho ambiental de produtos similares e de processos que executem uma mesma função visando à geração de subsídios para a tomada de decisão em diversos níveis.

Para esse trabalho foi escolhido o software Gabi 4 Software-System and Databases for Life Cycle Engineering, desenvolvido pela Universidade de Stuttgart, Echterdingen, onde para a etapa de avaliação de impacto foram utilizados os fatores de equivalência do método CML - Centrum voor Milieukunde Leiden.

As informações relacionadas à sistematização do inventário foram obtidas através de dados disponibilizados pelo banco de dados do ECOINVENT, de onde foram obtidos os fluxos de matéria e energia das fases denominadas do "berço ao portão", e finalmente pela 
Cetesb, de onde foram obtidas a eficiência e as emissões dos veículos automotivos. Para o cálculo, foi considerada uma unidade funcional de $100 \mathrm{~km}$ percorridos por um veículo automotivo do tipo flex fuel. Isto é, foram comparados $6,24 \mathrm{~kg}$ de gasolina tipo C, com $10,25 \mathrm{~kg}$ de etanol etílico hidratado.

Os resultados obtidos mostraram que a utilização de etanol etílico hidratado como combustível é visivelmente melhor em quase todas as categorias de impacto, com exceção apenas da categoria do uso do solo no quesito competição do uso. Esse resultado pode ser justificado pela elevada quantidade de substâncias tóxicas e potencialmente poluidoras, naturalmente presentes na composição do petróleo, somado ao fato da própria característica de não renovabilidade do recurso, que pela metodologia de análise de ciclo de vida já é considerada um impacto por si só.

3) IWAMOTO, F.; POSSARI, R. A. J. Análise da bioenergia da RAA através do PIR Estudo de caso: levantamento de usinas para integração de recursos na região administrativa de Araçatuba. 2009. Trabalho de Conclusão de Curso (Graduação em Engenharia) - Escola Politécnica da USP. Universidade de São Paulo, São Paulo, 2009.

Disponível em: 〈http://seeds.usp.br/portal/uploads/TF_Iwamoto_Juliano.pdf〉.

Resumo - Aplicação da metodologia PIR - Planejamento Integrado de Recursos para as usinas de açúcar e álcool da RAA, com intuito de confeccionar cenários futuros sobre os limites físicos e de qualidade ambiental regional, para a expansão da Bioenergia no oeste paulista.

Valoração da Bionergia da RAA: levantamento de usinas localizadas na região, com os respectivos dados encontrados nos relatórios de licenciamento ambiental dos 
empreendimentos e, no caso de não existência dos dados disponíveis, levantamento de valores teóricos junto à literatura e inferência de dados faltantes através de correlações;

Mapeamento Ambiental: levantamento das condições ambientais de qualidade regional, através de indicadores de sustentabilidade encontrados junto à literatura, publicações dos órgãos ambientais, institutos de pesquisa e estatística, entre outras instituições de pesquisa;

Integração de Recursos: a aplicação da metodologia PIR consiste em inter-relacionar os dados supracitados com o intuito de propor alternativas para o suprimento de demandas futuras de energia, com composições de RE melhor ranqueados no Processo de Análise Hierárquica, dentro dos limites físicos e de qualidade ambiental previstos no Mapeamento.

No escopo deste trabalho, não serão analisados todos os RE - Recursos Energéticos que constam na lista de REs valorados pelo PIR. Dessa forma, o intuito do trabalho é a aplicação da metodologia na projeção de diferentes alternativas de produção de bioenergia empregadas atualmente e definição de limites teóricos para expansão desses REs.

A comparação visa ainda definir alternativas melhores condicionadas para contribuir com o desenvolvimento sustentável, atendendo às necessidades regionais e de acordo com a estrutura de análise empregada no PIR.

O relatório técnico-científico sobre o Mapeamento Ambiental da RAA se encontra no link: 〈http://seeds.usp.br/fapesp/03064417/rtcpirnausp409.pdf>.

\subsection{Balanço Energoambiental da RAA}

O Balanço Energoambiental da Região Administrativa de Araçatuba é uma resposta às necessidades de dados e informações sobre a oferta e demanda de energia e a intrínseca 
relação destas com o meio ambiente. A concepção é baseada na confiabilidade da fonte de dados e informações para serem usadas como um instrumento de estudos e análises, decisões e opções no Oeste Paulista. Com isso, são apresentadas a oferta e a demanda de energia por fonte no período compreendido entre 2000 e 2008. Os dados são apresentados em tabelas e gráficos, buscando incentivar a interpretação mais intuitiva das informações de modo similar a outros balanços energéticos, possibilitando comparações diretas entre si.

No contexto ambiental do oeste paulista (ou melhor, ainda da RAA), além de abordar a oferta e a demanda de energia, também foi avaliado o uso do solo e foram estimadas as emissões de $\mathrm{CO} 2$, provindas da combustão de energéticos combustíveis, emissões de $\mathrm{N} 2 \mathrm{O}$, provindas de culturas agrícolas, emissões de $\mathrm{CH} 4$, cuja fonte são os bovinos, e ainda as emissões de $\mathrm{CO} 2$ e CH4, que grandes reservatórios de água das UHEs emitem.

É importante evidenciar que as informações dos energéticos estão disponibilizadas em suas unidades tradicionais e em tOE (tonelada de óleo equivalente), que é numericamente igual a 10 milhões de kcal, unidade adotada mundialmente.

O relatório técnico-científico sobre o Balanço Energoambiental se encontra no link: $<$ http://seeds.usp.br/fapesp/03064417/rtcpirnausp410.pdf $>$.

\subsection{Previsão de Demanda no PIRnaUSP}

A previsão da demanda de energia (ou previsão de mercado, no jargão tradicional do setor) no contexto da formulação e realização teórico-prática do PIRnaUSP, além de contar com as ferramentas tradicionais econométricas e mercadológicas, é resultado da realização de cenários. Isto significa, valha a redundância, que dentro do processo do PIRnaUSP, tanto de formulação de metodologias/modelagem/procedimentos como de aplicação e verificação desses instrumentos para a realização do PIR (no caso o PIR da RAA), a previsão da demanda 
é um produto que se obtém da construção de cenários energéticos de longo prazo dentro dos tempos definidos pelo próprio PIR (em torno de 30m anos). Ressalta-se ainda que no caso específico do PIRnaUSP, mesmo usando os cenários energéticos como instrumento para previsão, está prevista também a metodologia de engenharia dos usos finais para a elaboração de ditos cenários e, portanto, da previsão.

\subsubsection{Cenários Energéticos}

Um cenário energético é uma visão futura de condições que, ao ser construído, adotase como passos no horizonte de planejamento não necessariamente uma projeção das condições passadas e presentes do sistema, região ou país a que se aplicam, mas uma possibilidade de estudar como determinadas variáveis afetam o planejamento e as medidas que, tomadas em determinadas situações e determinados intervalos de tempo, fazem do planejamento feito um caminho robusto e com menos incertezas.

Os cenários energéticos são construídos com o objetivo de analisar a consistência do planejamento realizado ao longo de seu horizonte de tempo, verificando se os recursos energéticos em estudo atendem às necessidades ao longo do tempo e em períodos particulares do planejamento.

Dentro do PIR esse trabalho é feito com o intuito de determinar a previsão da demanda de energia no longo prazo, com vistas à integração dos recursos energéticos e, com isso, também validar o Plano Preferencial, ao se modelar demandas, impactos ambientais, sociais e econômicos resultantes do planejamento proposto.

Um cenário energético está intimamente ligado a um cenário socioeconômico no qual ele é construído em cima e a partir deste. Essa ligação se traduz em uma mudança nas 
próprias condições sociais e econômicas a partir do cenário energético analisado, proporcionando uma verificação interativa e iterativa das premissas do cenário-base.

Para um determinado cenário socioeconômico, pode-se satisfazer a demanda energética de muitas maneiras, considerando diferentes fontes e variadas formas de usos finais. Essas diferenças podem refletir-se na estrutura tarifária, nas leis em que se enquadram o uso do energético ou mesmo na quantidade de energia necessária para se atender a um determinado serviço energético.

Em um país em desenvolvimento, como é o caso do Brasil, tanto em uma análise federativa, como apenas se pensando de forma regional ou local, é leviano pensar que uma extrapolação no tempo de dados passados irá responder às demandas energéticas, sociais e

estruturais necessárias dentro do planejamento proposto. É necessário que sejam levantadas variáveis, como o crescimento populacional, o produto interno, a eficiência econômica (que se refere a uma melhor distribuição de renda), o nível de energização e a distribuição de energéticos, o acesso às novas tecnologias, as estruturas regulatórias e o crescimento da infraestrutura.

\subsubsection{Cenários Socioeconômicos}

Um cenário energético e todo o planejamento a que ele está sujeito, como já foi mencionado, depende intrinsecamente do cenário socioeconômico traçado para o horizonte de análise, sendo um processo iterativo entre as interações energéticas e sociais.

Para a composição de cenários socioeconômicos, é necessário que, dentro das variáveis que devem ser levantadas e avaliadas, estejam índices econômicos, sociais, estruturais e geográficos que, juntos, podem dar um panorama da região na qual está inserido o cenário em questão. 
Quanto maior a estratificação que se faz no cenário de partida, ou o ano-base, maiores as possibilidades de composição de cenários alternativos que podem prever intercâmbios de classes sociais, aumento do Produto Interno Bruto per capita, por classe ou setor de atividade. Também é necessário realizar o levantamento do atendimento desses setores de atividade por cada um dos energéticos em questão.

A consideração de mudanças no cenário mundial ou mesmo em blocos regionais deve ser inclusa na análise do cenário em questão, pois a globalização da economia, competição e cooperação entre regiões econômicas, fluxo de investimentos de grandes mercados influenciam diretamente qualquer prospecção futura. Assim como cenários contrastados podem cobrir mais possibilidades de acerto ao que se passa no futuro, também abrange um maior número de variáveis que pode inviabilizar o levantamento coerente de dados para responder ao planejamento. Existem três tipos de cenários:

\section{Cenários Tendenciais}

Os cenários tendenciais são prolongamentos dos índices históricos e de dados obtidos para a construção do ano-base, considerando diretrizes e políticas energéticas seguidas no presente da região, bem como índices de crescimento econômico e de demanda energética. 


\section{Cenários Preditivos}

Cenários preditivos são aqueles em que há a possibilidade de se analisar a interferência de uma ou mais ações conhecidas que devem ser tomadas ao longo do horizonte planejamento.

\section{Cenários Exploratórios}

Os cenários exploratórios possibilitam modificar a relação entre as variáveis que compõem o sistema e verificar quais os resultados dessa mudança.

A composição de cenários energéticos e socioeconômicos para a RAA gerou:

- Cenário Tendencial - cenário de projeção de fatores socioeconômicos atuais e perspectivas projetadas e sua respectiva previsão de demanda energética;

- Cenário Sustentável - consideração de fatores que buscam o desenvolvimento sustentável em todas as considerações socioeconômicas dentro do horizonte de planejamento e a sua respectiva previsão de demanda energética;

- Cenário Sustentável-Primoroso - extrapolação otimista das premissas do cenário sustentável e sua respectiva previsão de demanda;

- Cenário Otimista - extrapolação otimista das premissas do cenário tendencial e sua respectiva previsão de demanda.

\subsubsection{Dissertações de Mestrado}

A análise e sistematização dos cenários energéticos estão contidas em:

BERNAL, J. L. O. Modelagem para o aproveitamento sustentável dos biocombustíveis, energia eólica e solar dentro do PIR local: Estudo de caso do PIR da região de Araçatuba. 
2009. Dissertação (Mestrado em Energia) - Programa Interunidades de Pós-graduação em Energia da USP. Universidade de São Paulo, São Paulo, 2009.

Disponível em: http://www.teses.usp.br/teses/disponiveis/86/86131/tde-27092010-132126/ptbr.php

Resumo - O objetivo do trabalho é avaliar os recursos energéticos eólico, solar e biocombustíveis disponíveis na Região Administrativa de Araçatuba, através da metodologia de Planejamento Integrado de Recursos Energéticos, que busca sistematizar e qualificar os impactos inerentes à utilização energética, integrando a oferta e a demanda e buscando o menor custo completo, considerando as características de cada recurso energético nas dimensões ambiental, social, política e técnico-econômica. Trabalhando com a Previsão de Demanda para os cenários energéticos tendencial, sustentável, otimista e sustentávelprimoroso para a integração dos recursos energéticos ao longo do tempo e considerando os vigilantes do Mapeamento Energoambiental, buscando o atendimento de demanda local e de exportação de energia. Permitindo, assim, concluir que os recursos energéticos considerados

poderão atender aos requerimentos da demanda em todos os cenários, porém com a possibilidade de esgotamento em determinados cenários com horizonte de planejamento maiores que 30 anos.

\subsection{Integração de Recursos dentro do PIRnaUSP}

A integração de recursos energéticos no PIR é essencial para a formulação do plano preferencial no PIR. Sucintamente, a integração no PIR busca distribuir e qualificar os recursos ao longo do horizonte de planejamento, de acordo com o menor custo completo obtido a partir do Ranqueamento. A integração também se realiza com a previsão da demanda 
ao longo do tempo, tendo como resultado a satisfação das necessidades futuras de energia na região foco do PIR, no caso, da RAA.

A descrição procedimental da metodologia de Integração dos Recursos Energéticos também consta em Bernal (2009). Cabe ressaltar que o embasamento teórico-científico da engenharia da integração de recursos para o PIR foi definida essencialmente na tese de doutorado de André Luiz Veiga Gimenes (2004), sendo que no contexto do PIR da RAA e fundamentalmente no PIRnaUSP, a inclusão dos Vigilantes na integração de recursos procede a melhoramentos procedimentais e redefinições práticas da base estabelecida por Gimenes (2004).

\subsection{Plano Preferencial no PIR}

O plano preferencial integrado de recursos energéticos é o resultado de todas as etapas anteriores sistematizadas em um processo único, que busca o menor custo completo, visando atender as previsões de demanda obtidas nos diferentes cenários. Ele traz a caracterização da região, os recursos listados, selecionados, caracterizados, valorados e ranqueados, o mapeamento regional pró-energético, os cenários compostos das respectivas previsões de demanda e a integração dos recursos energéticos para o cenário tendencial e outras carteiras com opções de recursos para o tomador de decisões obter as informações mais embasadas sobre os riscos e as incertezas de cada carteira de recursos.

Os detalhamentos procedimentais do plano preferencial do PIRnaUSP, tendo como pano de fundo o PIR da RAA que responde ao projeto FAPESP acima mencionado, encontram-se na íntegra no relatório técnico-científico sobre o Plano Preferencial Integrado de Recursos Energéticos da RAA, que está no link: <http://seeds.usp.br/fapesp/03064417/rtcpirnausp402.pdf $>$. 


\subsubsection{Tese de Doutorado}

As correspondentes fundamentações metodológicas do Plano Preferencial dentro do PIR, a análise de riscos e as incertezas e principalmente a construção de carteiras de opções de recursos são trabalhadas na seguinte tese de doutorado:

BIAGUE, M. F. Modelagem da carteira dos recursos energéticos no PIR. Validação do modelo no PIR de Araçatuba. 2010. Tese (Doutorado em Engenharia) - Escola Politécnica da USP. Universidade de São Paulo, São Paulo, 2010.

Disponível em: http://www.teses.usp.br/teses/disponiveis/3/3143/tde-20082010-161027/ptbr.php.

Resumo - O objetivo desta tese é construir um modelo de composição de carteiras de recursos energéticos dentro do Planejamento Integrado de Recursos energéticos (PIR), aplicável em uma determinada região ou país. O modelo inclui as etapas de definição do espaço geográfico de estudo, o mapeamento de recursos, a caracterização dos recursos energéticos existentes e sua valoração. Após essas etapas, é feita a composição de carteiras energéticas, seguida pela construção de cenários e análise de riscos e incertezas para a definição da carteira preferencial dos recursos energéticos da região.

Como ferramentas de apoio, são adaptados os modelos matemáticos aplicados em sistemas financeiros para a seleção e análise de carteiras de investimentos, modelos para a avaliação de riscos e incertezas, o software de Planejamento de Alternativas Energéticas de Longo Alcance (LEAP), para a criação de cenários e previsão da demanda energética e o software Decision Lens (DL), para o Ranqueamento e a alocação de recursos financeiros dos recursos energéticos dentro da carteira definida, considerando as dimensões técnicoeconômica, ambiental, social e política. 
A caracterização dos recursos energéticos envolve o levantamento das características socioeconômicas, ambientais, o perfil dos envolvidos e interessados do setor energético, a listagem de recursos energéticos locais (hídricos, eólicos, solares, nucleares, biomassa, geotérmicas, células a combustíveis, dentre outros). Também são levantadas características construtivas das tecnologias existentes e que podem ser incorporadas na matriz energética da região em estudo.

O processo de avaliação dos potenciais energéticos envolve o cálculo dos potenciais energéticos teóricos de cada recurso energético existente na região. Após a avaliação dos potenciais, faz-se a priorização ou o Ranqueamento desses recursos através de critérios prédefinidos, em duas avaliações diferentes: Avaliação Determinística dos Custos Completos (ADCC) e Avaliação Holística dos Custos Completos (AHCC). Para gerar ambos os rankings, utiliza-se o software Decision Lens (DL) baseado no método do Processo de Análise Hierárquico (PAH). O cruzamento das avaliações resulta num ranking geral dos recursos energéticos, utilizado posteriormente para a construção de carteiras dos recursos energéticos.

$\mathrm{Na}$ valoração dos recursos energéticos, consideram-se atributos ambientais, sociais, técnico-econômicos e políticos, que podem afetar a formação de carteiras eficientes dentro do PIR em longo prazo. O resultado do processo de valoração é o potencial energético realizável da região em estudo.

Para esse potencial, aplica-se o modelo analítico de formação de carteiras de recursos energéticos. Neste são considerados o ranking, o volume de investimentos, os atributos ambientais (emissões), sociais (IDH, número de empregos, ocupação de solo), políticos (incentivos governamentais, impostos) e todos os parâmetros técnico-econômicos relacionados às tecnologias selecionadas para o aproveitamento de cada recurso energético. Com a incorporação dessas variáveis no modelo, são feitas simulações para a obtenção de 
carteiras ótimas para a construção do Plano Preferencial dentro do Planejamento Integrado dos Recursos energéticos.

\subsection{Plano de Negócios Cliente do PIRnaUSP}

O Plano de Negócios é considerado um produto natural do PIR realizado, mais especificamente, possui uma relação intrínseca com o Plano de Ação resultante do Plano Preferencial (revisto periodicamente ou, pelo menos, ano a ano). Deve-se enfatizar que um Plano de Negócios não é parte do PIR (assim como o Inventario prévio), porém este se aproveita completamente das informações qualificadas produzidas pelo PIR, não apenas as relativas ao Plano Preferencial, mas todas as partes dele. No caso prático do PIR da RAA, o Plano de Negócios aborda a possibilidade de aproveitamento dos recursos energéticos presentes na RAA, com potencial a serem considerados em planos de negócios em energia. Os principais elementos de um plano de negócios para a exploração dos recursos energéticos são: geração de energia, considerando o lado da oferta, e as medidas de economia de energia elétrica, pelo lado da demanda; e recolher e apresentar as informações relevantes para o desenvolvimento de planos de negócios para RAA que considerem os recursos energéticos a serem estudados (SILVA JR., 2012).

O relatório técnico-científico sobre o Plano de Negócios para os Recursos Energéticos da RAA se encontra no link: 〈http://seeds.usp.br/fapesp/03064417/rtcpirnausp411.pdf>.

\subsubsection{Dissertação de Mestrado em Andamento}

O Plano de Negócios para recursos energéticos dentro do PIR da RAA será discutido e detalhado na seguinte dissertação de mestrado: 
SILVA JR, B. Estudo e modelamento para avaliação de negócios energéticos sustentáveis para a região administrativa de Araçatuba/SP (oeste paulista), sendo que o depósito da sua versão final na CPG da Poli/USP foi realizado em 06/02/2012. 


\section{Contribuição da Cooperhidro para o PIRnaUSP}

Este item é para evidenciar que a realização plena do PIRnaUSP não é possível sem a concorrência de instituições e indivíduos (En-In). Tal afirmação é demonstrada, a longo deste item, através da contribuição da instituição parceira Cooperhidro, tanto para o desenvolvimento do projeto de pesquisa PIR da RAA como para efetivar a verificação das ferramentas componentes do PIRnaUSP na prática.

\subsection{A instituição}

A ONG Cooperativa do Polo Hidroviário de Araçatuba - Cooperhidro é uma agência de desenvolvimento regional, com organização privada, independente e sem fins lucrativos. Fundada em 1995, tem suas ações e atividades voltadas a identificar, criar e mapear oportunidades de negócios na região, promovendo o aproveitamento estratégico das potencialidades e infraestrutura regional, com foco no desenvolvimento sustentável e na preservação ambiental.

Na região do oeste paulista atua sob a cooperação e parceria com os governos federal e estadual em mais de 40 municípios, desenvolvendo projetos, aquecendo o mercado e assessorando a adequada inserção de empreendimentos voltados à sustentabilidade.

\subsection{A Intersecção de Interesses na Região de Araçatuba}

A Região Administrativa de Araçatuba, interior do estado de São Paulo, oeste paulista, situada na região do Baixo-Tietê, composta de 43 municípios e com perfil agroindustrial, com 
destaque para a agricultura da cana-de-açúcar e pecuária, ressurge para o cenário nacional de investimentos sob o destaque do potencial energético e pelas condições favoráveis de se produzir energia, observando os aspectos de sustentabilidade.

Situada no importante eixo de infraestrutura do estado de São Paulo, composto de rodovias, gasodutos, abundância hídrica e complexo de hidrelétricas, a região de Araçatuba iniciou no ano de 2004 a parceria e cooperação com a Universidade de São Paulo, através do Gepea e IEE, visando dotar a região de uma base de conhecimento voltada à potencialização e à ampliação de suas fontes energéticas produtivas existentes, e também de novas fontes renováveis e que poderiam colaborar para o desenvolvimento regional sustentável.

\subsection{A Cooperhidro no Projeto FAPESP 03/06441-7}

Dentro do escopo do projeto, a instituição atuou em todas as etapas de execução dos trabalhos de pesquisa de campo (in loco), ora como facilitadora de contatos com entidades locais detentoras de dados importantes ao andamento do projeto, tais como os levantamentos regionais para construção do inventário ambiental prévio e listagem, peneiramento e seleção de recursos energéticos, ora como entidade responsável pela execução técnica de tarefas vinculadas ao projeto, como identificação dos envolvidos-interessados (En-In) da região e envolvimento destes com o projeto através de diversas oficinas, treinamentos técnicos, simpósios e do evento final, a " $1^{\text {a }}$ Conferência sobre Planejamento Integrado de Recursos Energéticos Regional - Em foco o Desenvolvimento Sustentável”, também sob o fomento da Fapesp (FAPESP n. 2009/08922-9).

Assim a entidade parceira ofereceu ao andamento do projeto, e com isso ao PIRnaUSP, a dedicação em tempo de pessoal especializado para o levantamento de dados técnicos, a execução de treinamentos técnicos com universitários, órgãos não governamentais, 
representantes de prefeituras da região e a sociedade organizada. Ofereceu ainda apoio institucional com a utilização de infraestrutura de trabalho, como computadores, espaço físico, acesso à internet e telefone. Ainda possibilitando o suporte à execução da Análise de Custos Completos através da participação de todos os envolvidos e interessados para a consolidação dos dados como forma amostral de toda a sociedade organizada da RAA, no que diz respeito a energia, meio ambiente, organizações não governamentais, poder público local, regional e esferas superiores, além das instituições de ensino amplamente envolvidas no desenvolvimento dos trabalhos. 


\section{Transferência de Conhecimento e Formação Especializada}

\subsection{Oficinas e Treinamentos Técnicos de PIRnaUSP}

No desenvolvimento dos trabalhos investigativos técnico-científicos e de engenharia do PIRnaUSP e também ao longo da vigência do projeto Fapesp vinculado, foram realizados cinco oficinas de PIR especificas e quatro treinamentos técnicos dentro das quatro dimensões consideradas e analisadas pela metodologia de PIR, com o intuito de realizar a transferência do conhecimento sobre a região no que diz respeito aos recursos energéticos, aos fatores sociais, políticos e ambientais locais que interferem na escolha de determinado recurso, além de dados técnico-econômicos sobre todos os possíveis recursos a serem aproveitados na região.

As oficinas de PIR e os treinamentos tinham como principais objetivos a transferência de conhecimento, realizada em duas vias, pois além da formação técnica dos especialistas para a RAA também se fazia necessária a contrapartida do conhecimento local dos ambientes políticos e sociais, bem como os detalhes técnicos sobre o meio ambiente e as possíveis instalações de recursos energéticos. Ainda objetivava a captação da impressão desses especialistas sobre a possibilidade de inserção dos recursos na região, através da realização de dinâmicas para aferição de opções individuais para a construção da ACC em todas as dimensões de análise do PIR.

Os relatórios sobre os treinamentos técnicos para o PIR se encontram nos links:

〈http://seeds.usp.br/fapesp/03064417/rtcpirnausp109.pdf>;

<http://seeds.usp.br/fapesp/03064417/rtcpirnausp118.pdf>;

<http://seeds.usp.br/fapesp/03064417/rtcpirnausp211.pdf>; 
〈http://seeds.usp.br/fapesp/03064417/rtcpirnausp212.pdf $>$.

Já os relatórios sobre as oficinas de PIR, orientadas a princípio para a dinâmica de aferição de opções para a construção da ACC, encontram-se nos links:

<http://seeds.usp.br/fapesp/03064417/rtcpirnausp115.pdf>;

<http://seeds.usp.br/fapesp/03064417/rtcpirnausp116.pdf>;

$<$ http://seeds.usp.br/fapesp/03064417/rtcpirnausp210.pdf >;

<http://seeds.usp.br/fapesp/03064417/rtcpirnausp209.pdf $>$.

\subsection{Efeito Local - Simpósios de Água e Energia}

O efeito local pode ser medido definitivamente através da atuação da entidade parceira ao longo da realização dos trabalhos de PIRnaUSP, a Cooperhidro: ONG da RAA que inclusive assinou formalizando sua participação no projeto Fapesp de PIR da RAA. Assim, a Cooperhidro passou, ao longo da vigência do projeto e então de forma definitiva, a organizar simpósios anuais com o intuito de reunir os formadores de políticas públicas, especialistas em energia, meio ambiente e a sociedade em geral para discussões sobre as direções a serem seguidas pelos tomadores de decisão locais, sob a supervisão e participação das entidades locais e da sociedade, gerando a possibilidade local de divulgação ampla através de mídia impressa das premissas do projeto (cf. COOPERHIDRO, 2004, 2006, 2007, 2008 e 2009). Dessa forma, o debate foi ampliado no entorno dos temas necessários à participação da sociedade organizada no processo de planejamento energético preconizados pela metodologia do PIR. 


\section{Políticas Públicas}

O PIRnaUSP, como já mencionado, tem como âncora fundamental o projeto FAPESP 03/06441-7, que é parte do Programa de Pesquisa em Políticas Públicas da Fapesp. Nesse sentido, fica evidente que os trabalhos de pesquisa, direta e indiretamente relacionados, de PIRnaUSP, tem como eixo principal esse projeto de pesquisa e fundamentalmente o PIR da RAA.

Voltado ao planejamento energético, visando o desenvolvimento sustentável através da consideração, a priori, de aspectos sociais, ambientais e políticos associados aos já consolidados técnico-econômicos, o PIR traz como resultado o Plano Preferencial Integrado de Recursos Energéticos (ou simplesmente "Plano Preferencial", no jargão do PIRnaUSP), que deve servir como um guia aos tomadores de decisão que irão implantar tais recursos ao longo do horizonte de planejamento e com o objetivo de atendimento à previsão de demanda energética regional. Além disso, este serve como instrumento de participação e cobrança de resultados aos tomadores de decisão por parte da sociedade civil organizada e em geral.

Para a RAA, principalmente no município de Araçatuba, algumas políticas públicas, tanto voltadas à implementação dos resultados do projeto FAPESP 03/06441-7, quanto se valendo de resultados intermediários alcançados com algumas das diversas metodologias utilizadas, como políticas municipais, formas de aproveitamento de recursos energéticos previstos e valorados pela metodologia e outros resultados, podem ser observadas no Relatório de Resultados da parceria com a Cooperhidro, que se encontra no link:

〈http://seeds.usp.br/fapesp/03064417/rtcpirnausp425.pdf $>$. 


\section{Produção Técnico-científica do PIRnaUSP}

Pode-se afirmar que o PIR, como PIRnaUSP com suas ferramentas, metodologias, modelagens e procedimentos relativos aos módulos componentes do PIR, tais como os aqui mencionados, tem pelo menos uma década de atividades. Até o presente, tem-se em finalização, em atualização e concluídos, em termos de pesquisadores/profissionais (RH), formandos, trabalhos técnicos, metodologias, procedimentos etc., produtos tais como os listados descritivamente nos itens a seguir:

\subsection{Teses e doutores}

- $\quad$ André Luiz Veiga Gimenes

Título: Modelo de integração de recursos como instrumento para um planejamento energético. Resultado: tese de doutorado apresentada à EPUSP (Engenharia Elétrica) em maio de 2004 (início: fevereiro/ 2000). Coorientadores: prof. dr. Lineu Belico dos Reis e prof. dr. Miguel Edgar Morales Udaeta. Financiamento: CAPES.

- $\quad$ Paulo Hélio Kanayama

Título: Mecanismos de desenvolvimento limpo no planejamento integrado de recursos energéticos. Resultado: tese de doutorado apresentada à EPUSP (Engenharia Elétrica) em abril de 2007 (início: em abril/ 2003). Orientador: prof. dr. Miguel Edgar Morales Udaeta. Financiamento: CNPq. 
- $\quad$ Mário Fernandes Biague

Título: Modelagem da carteira de recursos energéticos dentro do planejamento integrado dos recursos energéticos (PIR). Resultado: tese de doutorado apresentada à EPUSP (Engenharia Elétrica) em maio de 2010 (início: janeiro/ 2005). Orientador: prof. dr. Miguel Edgar Morales Udaeta. Financiamento: PEA/EPUSP.

- Pascoal Henrique da Costa Rigolin

Título: Análise e desenvolvimento de um sistema para classificar (ranquear) RELOs e RELDs com base no cômputo e valoração do potencial completo dos recursos energéticos dentro do PIR. Resultado: em andamento desde março de 2008 na EPUSP (Engenharia Elétrica). Orientador: Prof. Dr. Miguel Edgar Morales Udaeta. Financiamento: CAPES.

- $\quad$ Ricardo Lacerda Baitelo

Título: Modelo de valoração e cômputo de potenciais completos de recursos energéticos para o PIR. Resultado: tese de doutorado apresentada à EPUSP (Engenharia Elétrica) em abril de 2011 (início: março/ 2006). Orientador: prof. dr. Luiz Claudio Ribeiro Galvão; coorientador: prof. dr. Miguel Edgar Morales Udaeta. Financiamento: PEA/EPUSP durante 2006.

- $\quad$ Flavio Marques Azevedo

Título: Modelagem e implementação de um sistema de análise geoenergética sob a visão do planejamento integrado de recursos - PIR. Resultado: em andamento desde março 
de 2009 na EPUSP (Engenharia Elétrica). Orientador: prof. dr. José Aquiles Baesso Grimoni; coorientador: prof. dr. Miguel Edgar Morales Udaeta. Financiamento: próprio.

\subsection{Dissertações e mestres}

\section{- $\quad$ Ricardo Junqueira Fujii}

Título: Modelo de caracterização sistêmica das opções de oferta energética para o PIR. Resultado: dissertação de mestrado apresentada à EPUSP (Engenharia Elétrica) em setembro de 2006 (início: setembro/ 2003). Orientador: prof. dr. Miguel Edgar Morales Udaeta. Financiamento: PEA/EPUSP.

\section{- $\quad$ Ricardo Lacerda Baitelo}

Título: Modelagem completa e análise dos recursos energéticos do lado da demanda para o PIR. Resultado: dissertação de mestrado apresentada à EPUSP (Engenharia Elétrica) em fevereiro de 2006 (início: setembro/ 2003). Orientador: prof. dr. Miguel Edgar Morales Udaeta. Financiamento: PEA/EPUSP.

- Jonathas Luiz de Oliveira Bernal

Título: Biocombustíveis, fontes de energia eólica e solar dentro do planejamento integrado de recursos regional. Resultado: dissertação de mestrado apresentada no PIPGE/USP (Energia) em agosto de 2009 (início: abril/ 2007). Orientador: prof. dr. Miguel Edgar Morales Udaeta. Financiamento: ANP (PRH-ANP/04). Orientador: Miguel Edgar Morales Udaeta. 
- $\quad$ Barnabé da Silva Junior

Título: Estudo e modelamento para avaliação de negócios energéticos sustentáveis para a região administrativa de Araçatuba/SP (oeste paulista). Resultado: dissertação de mestrado apresentada à EPUSP (Engenharia Elétrica) em fevereiro de 2012 (início: janeiro/ 2009). Orientador: prof. dr. Miguel Edgar Morales Udaeta. Financiamento: próprio.

- $\quad$ Decio Cicone Junior

Título: Modelagem e aplicação da avaliação de custos completos através do método de análise hierárquica dentro do planejamento integrado de recursos. Resultado: dissertação de mestrado apresentada à EPUSP (Engenharia Elétrica) em agosto de 2008 (início: setembro/ 2007). Orientador: Prof. Dr. Miguel Edgar Morales Udaeta. Financiamento: próprio.

\subsection{Trabalhos de Formatura e Graduados}

- Jonathas Luiz de Oliveira Bernal

Título: Avaliação prévia para novos instrumentos de planejamento energético regional visando o desenvolvimento sustentável. Objetivo: identificar recursos energéticos distribuídos que ainda não foram aproveitados na região e articular seus benefícios, considerando, inclusive, as possibilidades oferecidas pelas fontes alternativas para atender a demanda local, visando o desenvolvimento sustentável através de mecanismos de desenvolvimento limpo.

Resultado: projeto de formatura apresentado ao curso de graduação em Engenharia Elétrica da Faculdade de Engenharia do Campus de Guaratinguetá, Unesp, e aprovado em 
dezembro de 2006. Financiadora: IEE/USP. Período: ano de 2006. Orientação: prof. dr. Miguel Edgar Morales Udaeta e prof. dr. José Celso Freire Jr.

- $\quad$ Maurício Guimarães Sabbag

Título: Produção e uso sustentável do biodiesel integrado a usinas do setor sucroalcooleiro - Piloto de empreendimento-modelo. Objetivo: minimizar emissões de poluentes e maximizar desenvolvimento através do aproveitamento dos biocombustíveis, inserindo-os na matriz energética brasileira. $\mathrm{O}$ trabalho inclui análise de empreendimentomodelo produtor de biodiesel integrado às usinas e destilarias de Araçatuba, oeste paulista.

Resultado: projeto de formatura apresentado à Escola Politécnica da USP (Engenharia Ambiental) e aprovado em dezembro de 2006. Financiadora: ANP (PRH-ANP/04). Período: ano de 2006. Orientação: prof $^{a}$ dra. Patrícia Helena Lara dos Santos Matai e prof. dr. Miguel Edgar Morales Udaeta.

- $\quad$ Alexandre Ruiz Picchi

Título: Análise, mitigação e potencialização dos impactos e efeitos ambientais causados por usinas termoelétricas a gás natural em grandes metrópoles/cidades. Objetivo: para verificar a viabilidade ambiental das termelétricas, torna-se necessária uma avaliação de impacto ambiental, utilizando-se de recursos como o Estudo de Impacto Ambiental. Essa avaliação é composta da identificação e caracterização dos efeitos e impactos ambientais e das alternativas de mitigação e potencialização dos impactos. Em sequência, haverá a elaboração de um modelo para aplicação do Estudo de Impacto Ambiental, para complementação do processo de Avaliação de Impacto Ambiental. 
Resultado: projeto de formatura apresentado à Escola Politécnica da USP (Engenharia Ambiental) e aprovado em dezembro de 2006. Financiadora: ANP (PRH-ANP/04). Período: ano de 2006. Orientação: prof ${ }^{a}$ dra. Patrícia Helena Lara dos Santos Matai e prof. dr. Miguel Edgar Morales Udaeta.

- $\quad$ Raquel Gomes Brito Rodrigues

Título: Análise do cenário atual e aspectos de demanda do gás natural - Carteira de recursos energéticos visando o gás natural dentro do PIR da região de Araçatuba. Objetivo: identificar, analisar e consolidar todos os fatores relacionados à indústria energética, mais especificamente à cadeia produtiva do gás natural, visando a determinação de aspectos econômicos, sociais, ambientais e políticos do recurso no cenário atual; simular cenários para o atendimento da demanda da região administrativa de Araçatuba, buscando a otimização no abastecimento energético através do gás natural; auxiliar a construção do PIR no Estado de São Paulo.

Resultado: projeto de formatura apresentado à EPUSP (Engenharia de Energia e Automação Elétricas) e aprovado em dezembro de 2007. Financiadora: PEA/ESPUSP. Período: ano de 2007. Orientação: prof. dr. Miguel Edgar Morales Udaeta.

- $\quad$ Frederico Augusto Anea Sergio

Título: Arquitetura e implementação do modelo computacional energético de mina para dados para o planejamento energético. Objetivo: elaboração e implementação de um modelo completo e compacto de mina de dados para armazenamento e consulta das informações, tais como técnicas, econômicas, sociais e ambientais. Esse banco de dados visa garantir agilidade e facilidade de interação, assim como solidez e segurança dos dados. 
Resultado: projeto de formatura apresentado à EPUSP (Engenharia de Energia e Automação Elétricas) e aprovado em fevereiro de 2008. Financiadora: ANP (PRH-ANP/04). Período: desde 2007. Orientação: prof. dr. Miguel Edgar Morales Udaeta.

\section{- $\quad$ Alex Leão Genovese}

Título: Análise do gás natural liquefeito como alternativa para a segurança do suprimento energético brasileiro. Objetivo: avaliar o cenário atual do gás natural (GN) no Brasil, com enfoque no possível desenvolvimento de um mercado para o gás natural liquefeito (GNL) como alternativa para a garantia do atendimento à crescente demanda desse recurso energético no país. Para tanto, serão analisados o mercado global do GNL, o desenvolvimento tecnológico desta indústria ao longo dos anos e os custos associados em cada etapa da sua cadeia de produção. Com base nessas análises, serão apresentadas estimativas para as tendências desse mercado no médio prazo, com relação à capacidade global de produção, transporte e regaseificação de GNL. Com isso, será possível avaliar as oportunidades que o GNL traz para o Brasil, sob o prisma da segurança no suprimento energético nacional.

Resultado: projeto de formatura apresentado à EPUSP (Engenharia de Energia e Automação Elétricas) e aprovado em dezembro de 2008. Financiadora: PEA/ESPUSP. Período: 2006-2007. Orientação: prof. dr. Miguel Edgar Morales Udaeta.

- $\quad$ Bruno Keiti Kuada Shimanoe

Título: Mapeamento e cálculo completo dos potenciais teóricos, realizáveis e do mercado dos recursos energéticos do lado da oferta para o PIR da RAA. Objetivo: levantar as diversas tecnologias existentes atualmente para produção de energia através de variadas fontes, sejam elas renováveis ou não. Em seguida, para o PIR da RAA, deve-se avaliar o 
potencial teórico; avaliar o potencial realizável; avaliar o potencial de mercado; identificar as séries históricas de todas as características dos RELOs (Recursos Energéticos do Lado da Oferta), de pelo menos 10 anos; construir a seleção dos recursos, segundo seu menor custo completo RAA.

Resultado: projeto de formatura apresentado à EPUSP (Engenharia de Energia e Automação Elétricas) e aprovado em dezembro de 2007. Financiadora: PEA/ESPUSP. Período: 2006-2007. Orientação: Prof. Dr. Miguel Edgar Morales Udaeta.

- Janaína Roldão de Souza

Título: Tutela jurídica dos recursos hídricos vinculada ao projeto: Novos instrumentos de planejamento energético regional visando o desenvolvimento sustentável. Objetivo: discorrer sobre os recursos hídricos e sua importância; conceituar os valores atribuídos aos recursos hídricos; analisar questões relacionadas à utilização dos recursos hídricos; identificar o potencial dos recursos hídricos na região de Araçatuba; fazer o levantamento histórico sobre a tutela jurídica da água; levantar os dispositivos legais pertinentes aos recursos hídricos; interpretar a legislação que tutela os recursos hídricos; analisar a atual situação dos recursos hídricos no oeste paulista; ligação e importância dos recursos hídricos para o setor energético; expor ideias e sugestões sobre as condições dos recursos hídricos atualmente.

Resultado: projeto de formatura apresentado no Centro Universitário Toledo (Direito) em dezembro de 2008. Financiadora: Fapesp. Período: 2007-2008. Coorientação: prof. dr. Miguel Edgar Morales Udaeta. 
- $\quad$ Alexandre Orrico Reinig

Título: Aplicação da ACC no PIR visando o gás natural e outros energéticos não renováveis para a região administrativa de Araçatuba. Objetivo: aplicar a Análise de Custos Completos, amparada pela Metodologia de Análise Hierárquica, no Planejamento Integrado de Recursos Energéticos e avaliação da viabilidade do Gás natural e Derivados como o Óleo Diesel como fontes energéticas para a RAA. Obtenção, através da utilização da metodologia ACC amparada pelo MAH e uso de software específico, de um ranking de recursos energéticos para a Região Administrativa de Araçatuba visando o desenvolvimento sustentável. E análise da viabilidade e importância do uso de gás natural, biocombustível e óleo diesel como fontes de recursos energéticos frente outras fontes de energia.

Resultado: projeto de formatura apresentado à Escola Politécnica da USP (Engenharia de Energia e Automação Elétricas) dezembro de 2008. Financiadora: ANP (PRH-ANP/04). Período: 2007-2008. Orientação: prof. dr. Miguel Edgar Morales Udaeta.

- $\quad$ Fernando Muccioli de Mello

Título: Inventário dos impactos ambientais provenientes de empreendimentos energéticos na região administrativa de Araçatuba-SP. Objetivo: neste trabalho será feito o levantamento e análise, sob a ótica do PIR, do inventário dos impactos ambientais causados por empreendimentos energéticos na região administrativa de Araçatuba-SP com os seguintes objetivos: identificar e quantificar os impactos; comparar os impactos apurados com impactos provenientes de formas alternativas e convencionais de energia; apontar opções energéticas menos impactantes na região; descrever as vantagens e desvantagens das opções energéticas indicadas. 
Resultado: projeto de formatura apresentado à EPUSP (Engenharia de Energia e Automação Elétricas) em agosto de 2009. Financiadora: ANP (PRH-ANP/04). Período: 20082009. Orientação: prof. dr. Miguel Edgar Morales Udaeta.

\section{- $\quad$ Felipe Coelho Costa}

Título: Avaliação da cadeia produtiva do biodiesel e seus efeitos na produção e mercado de alimentos - Estudo de caso: PIR na região administrativa de Araçatuba. Objetivo: analisar quantitativamente e holisticamente a produção sustentável do biodiesel na região administrativa de Araçatuba, visando à vocação produtora de energia da região e sua competitividade perante outros biocombustíveis. Descrever a cadeia produtiva do biodiesel; determinar o potencial de produção de biodiesel na região administrativa de Araçatuba dentro do PIR; levantar o universo de dados e produzir séries históricas dos últimos 10 anos da região de Araçatuba, para determinar o mercado real de biodiesel da região; avaliar os custos completos do biodiesel e sua introdução no mercado; determinar o modelo produtivo característico para região; quantificar os impactos ambientais locais, regionais e globais do uso do potencial energético regional; Identificar as necessidades ou expectativas estratégicas da região; analisar a sustentabilidade entre a produção de bioenergia e a produção de alimentos.

Resultado: projeto de formatura apresentado à EPUSP (Engenharia Ambiental) em 2009. Financiadora: ANP (PRH-ANP/04). Período: 2007-2009. Orientação: Prof. Dr. Miguel Edgar Morales Udaeta. 
- $\quad$ Alexandre Malta Tedaldi

Título: Avaliação do potencial completo de pequenos aproveitamentos energético usando biocombustíveis: estudo comparativo com o gás natural. Objetivo: o objetivo desse estudo é avaliar o potencial de pequenos aproveitamentos de biocombustíveis na Região Administrativa de Araçatuba para microgeração de energia elétrica de potências de até 500 kW, fazendo um comparativo com o uso do gás natural. As tecnologias de geração elétricas mais adequadas à geração nessa faixa de potência são os motores a combustão interna, as microturbinas e as turbinas a vapor. Os motores se configuram em uma opção de investimento relativamente baixo e com ampla disponibilidade comercial. As microturbinas requerem alto investimento e tem disponibilidade comercial baixa e as turbinas a vapor tem pouca disponibilidade para a faixa de potência adotada.

Resultado: projeto de formatura apresentado à Escola Politécnica da USP (Engenharia de Energia e Automação Elétricas) e aprovado em dezembro de 2010. Financiadora: ANP. Período: desde 2008. Orientação: Miguel Edgar Morales Udaeta.

\section{Rafael Dias Torres}

Título: Modelagem da arquitetura bioclimática local como recurso energético dentro do PIR da região administrativa de Araçatuba. Objetivo: o trabalho tem como objetivo caracterizar a arquitetura bioclimática como um recurso energético pelo lado da demanda. Isso é feito dentro do Planejamento Integrado de Recursos (PIR) para a Região Administrativa de Araçatuba (RAA); onde se busca metodologicamente as possibilidades de economia de energia independente da tecnologia utilizada, pensando no planejamento do todo sem delimitar a preocupação no levantamento dos casos individuais para efeito de computo e 
valoração do potencial completo desse recurso energético do lado da demanda levando-se em conta as dimensões social, ambiental, política e técnico-econômica.

Resultado: projeto de formatura apresentado à Escola Politécnica da USP (Engenharia de Energia e Automação Elétricas) e aprovado em dezembro de 2010. Financiadora: autônomo. Período: desde 2009. Orientação: Miguel Edgar Morales Udaeta.

\subsection{Iniciação Científica e Pesquisador}

1) Nome: Raquel Gomes Brito Rodrigues (graduação na Engenharia Elétrica/USP).

Tema: Sistema de análise geoenergética aplicada ao gás natural

Financiadora: PEA/EPUSP

Período: de junho de 2004 a dezembro de 2005

Orientação: Miguel Edgar Morales Udaeta

2) Nome: Alex Leão Genovese (graduação em Engenharia Elétrica/USP)

Tema: Desenvolvimento da usina de dados/LEAP para o SAGe (Sistema de Análise Geoenergética)

Financiadora: PEA/EPUSP

Período: de abril de 2004 a fevereiro de 2006

Orientação: Miguel Edgar Morales Udaeta 
3) Nome: Maurício Guimarães Sabbag (graduação em Engenharia Ambiental/USP)

Tema: Produção e uso sustentável de biocombustíveis - Estudo piloto de empreendimento-modelo

Financiadora: ANP (dentro do PRH-ANP/04 no IEE/USP)

Período: de agosto de 2005 a fevereiro de 2007

Orientação: Miguel Edgar Morales Udaeta

4) Nome: Alexandre Ruiz Picchi (graduação em Engenharia Ambiental/USP)

Tema: Análise e mitigação dos impactos ambientais causados por usinas termoelétricas a gás natural em grandes metrópoles

Financiadora: ANP (dentro do PRH-ANP/04 no IEE/USP)

Período: de agosto de 2005 a fevereiro de 2007

Orientação: Patrícia Helena Lara dos Santos Matai e Miguel Edgar Morales Udaeta

5) Nome: Bruno Madeira Cruz (graduação em Geografia/USP)

Tema: Geoprocessamento aplicado ao planejamento energético regional

Financiadora: PEA/EPUSP

Período: de junho de 2006 a dezembro de 2006

Orientação: Miguel Edgar Morales Udaeta 
6) Nome: Alexandre Orrico Reinig (graduação em Engenharia Elétrica/USP)

Tema: Aplicação da ACC no PIR visando o gás natural e outros energéticos não renováveis para a região administrativa de Araçatuba

Financiadora: ANP (dentro do PRH-ANP/04 no IEE/USP)

Período: de março de 2007 a fevereiro de 2009

Orientação: Miguel Edgar Morales Udaeta

7) Nome: Felipe Coelho Costa (graduação em Engenharia Ambiental/USP)

Tema: A cadeia produtiva do biodiesel e seus efeitos na produção de alimentos

Financiadora: ANP (dentro do PRH-ANP/04 no IEE/USP)

Período: de março de 2007 a fevereiro de 2009

Orientação: Miguel Edgar Morales Udaeta

8) Nome: Fatuma Catherine Atieno Odongo (graduação em Medicina/USP)

Tema: Caracterização dos efeitos a saúde humana devido ao uso dos recursos energéticos dentro do PIR (Planejamento Integrado de Recursos) para a região oeste paulista

Financiadora: Fapesp

Período: 2007-2008

Orientação: Miguel Edgar Morales Udaeta 
9) Nome: Martim Debs Galvão (graduação em História/USP)

Tema: Dimensão política do PIR para a usina de dados no SAGe - Métodos e bases de informações

Financiadora: PEA/EPUSP

Período: de março de 2007 a fevereiro de 2009

Orientação: Miguel Edgar Morales Udaeta

10) Nome: Thiago Hiroshi de Oliveira (graduação em Engenharia Ambiental/USP)

Tema: Modelagem sistêmica do mapeamento energoambiental para o PIR Araçatuba

Financiadora: PEA/EPUSP

Período: de novembro de 2006 até dezembro de 2007

Orientação: Miguel Edgar Morales Udaeta

11) Nome: Isabel Akemi Bueno Sado (graduação em Engenharia Ambiental/USP)

Tema: Potencialidade energética do biogás: Inventário e análise de custos completos dentro do planejamento integrado de recursos energéticos da região de oeste de São Paulo

Financiadora: ANP (dentro do PRH-ANP/04 no IEE/USP)

Período: de março de 2007 a fevereiro de 2009

Orientação: Miguel Edgar Morales Udaeta

12) Nome: Giselle Teles (graduação em Geografia/USP) 
Tema: Análise geoenergética cartográfica urbano/rural para o PIR da RAA

Financiadora: PEA/EPUSP

Período: de junho de 2006 até março de 2008

Orientação: Miguel Edgar Morales Udaeta

13) Nome: Julia Marques Bellacosa (graduação em Geografia/USP)

Tema: Diagnóstico dos envolvidos e interessados no planejamento integrado de recursos energéticos da $R A A$

Financiadora: PEA/EPUSP

Período: de junho de 2006 a dezembro de 2008

Orientação: Luiz Claudio Ribeiro Galvão e Miguel Edgar Morales Udaeta

14) Nome: Felipe Iwamoto (graduação em Engenharia Ambiental/USP)

Tema: Modelamento energoambiental para o mapeamento dos meios aéreo e terrestre no PIR da RAA

Financiadora: PEA/EPUSP

Período: de setembro de 2008 a agosto de 2010

Orientação: Miguel Edgar Morales Udaeta

15) Nome: Rafael Augusto Possari Juliano (graduação em Engenharia Ambiental/USP) 
Tema: Caracterização completa dos recursos energéticos e mapeamento no PIR de Araçatuba

Financiadora: PEA/EPUSP em 2008 e, em 2009, ANP (dentro do PRH-ANP/04 no IEE/USP).

Período: de março de 2008 a março de 2010

Orientação: Miguel Edgar Morales Udaeta

16) Nome: Thadeu Hiroshi Ferraz (graduação em Engenharia Ambiental/USP)

Tema: Modelamento energoambiental para o mapeamento dos meios antrópico $e$ aquático no PIR da RAA

Financiadora: ANP (dentro do PRH-ANP/04 no IEE/USP)

Período: de novembro de 2008 a outubro de 2009

Orientação: Miguel Edgar Morales Udaeta

17) Nome: Alexandre Malta Tedaldi (graduação em Engenharia Elétrica/USP)

Tema: Planejamento de longo prazo de alternativas energéticas

Financiadora: ANP (dentro do PRH-ANP/04 no IEE/USP)

Período: em andamento desde novembro de 2008

Orientação: Miguel Edgar Morales Udaeta

18) Nome: Fernando Muccioli de Mello (graduação em Engenharia Elétrica/USP) 
Tema: Impactos ambientais dos empreendimentos energéticos na RA Araçatuba

Financiadora: ANP (dentro do PRH-ANP/04 no IEE/USP)

Período: outubro de 2008 a setembro de 2009

Orientação: Miguel Edgar Morales Udaeta

19) Nome: Renata Valério Freitas (graduação em Engenharia Elétrica/USP)

Tema: Construção e implementação dos RELDs para o sistema de análise geoenergética

Financiadora: PEA/EPUSP

Período: de setembro de 2007 a agosto de 2009

Orientação: Miguel Edgar Morales Udaeta

\subsection{Publicações em Periódicos (Anexo A1)}

MASSARA, V.M.; FAGÁ, M.T.W.; UDAETA, M.E.M. Indicadores urbanos na previsão de expansão da rede canalizada de gás natural. Bahia Análise \& Dados. v. 16 (ISSN 0101-5397), p. $159 \quad-\quad 2006 . \quad 164, \quad$ Disponível em: 〈http://seeds.usp.br/fapesp/03064417/anexo1rtc40101.pdf>.

MASSARA, V.M.; UDAETA, M.E.M.; KANAYAMA, P.H.; GALVÃO, L.C.R. Expansão da rede de gás natural dentro do planejamento energético e urbano por meio do método de análise hierárquica e da dinâmica das cidades. Ciência \& Engenharia (ISSN 0103-944X; 
ISSN eletrônico 1983-4071), v. 17, n. 1/2, p. 43 - 50, jan. - dez. 2008. Disponível em: <http://seeds.usp.br/fapesp/03064417/anexo1rtc40102.pdf $>$.

GIMENES, A.L.V.; UDAETA, M.E.M.; GALVÃO, L.C.R. Modelo de integração de recursos para externalidades no planejamento energético. EletroEvolução (Rio de Janeiro). v. 46 (ISSN: 1806-1877), p. 61-67, 2007. Disponível em: <http://seeds.usp.br/fapesp/03064417/anexo1rtc40103.pdf $>$.

HEIDEIER, R. B.; UEOCKA, M. Z.; UDAETA, M. E. M. Análise e avaliação do mercado reprimido de energia no contexto do desenvolvimento limpo na região administrativa de Araçatuba. RAP - Revista de Administração Pública (FGV). v. 43 (ISSN 00347612), julho/agosto 2009. Disponível em: <http://seeds.usp.br/fapesp/03064417/anexo1rtc40104.pdf>.

NETO, J.A.A.; GRIMONI， J.A.B.; UDAETA， M.E.M.; MILLER， R.B. Análise da renovabilidade dos recursos físicos da terra na região administrativa de Araçatuba. Sinergia Revista do Centro Federal de Educação Tecnológica (ISSN: 1677-499X). v. 9, nº 1, janeirojunho de 2008. Disponível em: 〈http://seeds.usp.br/fapesp/03064417/anexo1rtc40105.pdf>.

CICONE JR., D.; UDAETA, M.E.M.; GRIMONI, J.A.B.; GALVÃO, L.C.R. Functionality of the approach of hierarchical analysis in the full cost accounting in the IRP of a metropolitan airport. Energy Policy. v. 36 (ISSN: 0301-4215), p. 991-998, 2008. Disponível em: <http://seeds.usp.br/fapesp/03064417/anexo1rtc40106.pdf $>$. 


\subsection{Anais de Congressos (Anexo A2)}

\subsubsection{Internacionais}

BURANI, G.F.; GRIMONI, J.A.B.; FAGÁ, M.T.W.; UDAETA, M.E.M. Thorough analysis of the current brazilian electric industry model. In: 28TH ANNUAL IAEE INTERNATIONAL CONFERENCE, 2005. Proceedings: Globalization of Energy: Markets, Technology, and Sustainability. Taipei: IAEE, 2005. Disponível em: <http://seeds.usp.br/fapesp/03064417/anexo2rtc40101.pdf $>$.

UDAETA, M.E.M.; FUJII, R.J.; GRIMONI, J.A.B.; BAITELO, R.L. Aspectos políticos e regulatórios do gerenciamento da demanda energética. In: VI CLAGTEE - SIXTH LATINAMERICAN CONGRESS ON ELECTRICITY GENERATION AND TRANSMISSION, Anais. Universidad Nacional de Mar del Plata (UNMDP). Mar del Plata - Argentina. 2005. Disponível em: <http://seeds.usp.br/fapesp/03064417/anexo2rtc40102.pdf>.

UDAETA, M.E.M.; BURANI, G.F.; GRIMONI, J.A.B.; BAITELO, R.L. Planejamento integrado de recurso no oeste do estado de São Paulo: Aplicação de avaliação dos custos completos e inclusão dos agentes do setor energético. In: VI CLAGTEE - SIXTH LATINAMERICAN CONGRESS ON ELECTRICITY GENERATION AND TRANSMISSION. Anais. Universidad Nacional de Mar del Plata (UNMDP). Mar del Plata - Argentina. 2005. Disponível em: 〈http://seeds.usp.br/fapesp/03064417/anexo2rtc40103.pdf>. 
FUJII, R.J.; UDAETA, M.E.M.; BURANI, G.F. Análise de elementos regulatórios relativos à geração distribuída. In: VI CLAGTEE - SIXTH LATIN-AMERICAN CONGRESS ON ELECTRICITY GENERATION AND TRANSMISSION. Anais. Universidad Nacional de Mar del Plata (UNMDP). Mar del Plata - Argentina. 2005. Disponível em: 〈http://seeds.usp.br/fapesp/03064417/anexo2rtc40104.pdf>.

FUJII, R.J.; UDAETA, M.E.M.; GALVÃO, L.C.R. Um modelo de caracterização sistêmica das opções de oferta energética. In: VI CLAGTEE - SIXTH LATIN-AMERICAN CONGRESS ON ELECTRICITY GENERATION AND TRANSMISSION. Anais. Universidad Nacional de Mar del Plata (UNMDP). Mar del Plata - Argentina. 2005. Disponível em: 〈http://seeds.usp.br/fapesp/03064417/anexo2rtc40105.pdf>.

BAITELO, R.L.; BURANI, G.F.; GRIMONI, J.A.B.; UDAETA, M.E.M. Modelo de caracterização e avaliação de recursos energéticos de demanda. In: VI CLAGTEE - SIXTH LATIN-AMERICAN CONGRESS ON ELECTRICITY GENERATION AND TRANSMISSION. Anais. Universidad Nacional de Mar del Plata (UNMDP). Mar del Plata Argentina. 2005. Disponível em: <http://seeds.usp.br/fapesp/03064417/anexo2rtc40106.pdf>.

INATOMI, T.A.H.; UDAETA, M.E.M. Análise dos impactos ambientais na produção de energia dentro do planejamento integrado de recursos. In: III WORKSHOP BRASIL-JAPÃO EM ENERGIA, MEIO AMBIENTE E DESENVOLVIMENTO SUSTENTÁVEL. Anais. Campinas - $\quad$ SP. $\quad$ UNICAMP, 2005. Disponível em: <http://seeds.usp.br/fapesp/03064417/anexo2rtc40107.pdf $>$. 
BURANI, G.F.; UDAETA, M.E.M.; KANAYAMA, P.H.; OLIVA, C.R.R.; AFFONSO, O.F. Uso racional e econômico da energia dentro de uma indústria metalúrgica: oportunidade de troca de eletricidade para gás natural. In: RIO OIL \& GAS EXPO AND CONFERENCE 2006. Proceedings. IBP - Instituto Brasileiro de Petróleo e Gás. Rio de Janeiro - Brasil, 2006. Disponível em: 〈http://seeds.usp.br/fapesp/03064417/anexo2rtc40108.pdf〉.

UDAETA, M.E.M.; FUJII, R.J.; BAITELO, R.L.; BURANI, G.F. Local integrated energy resources planning implementation process. In: 28TH ANNUAL IAEE INTERNATIONAL CONFERENCE. Proceedings. IAEE (International Association for Energy Economics). Potsdam/Alemanha, $2006 . \quad$ Disponível em: <http://seeds.usp.br/fapesp/03064417/anexo2rtc40109.pdf $>$.

UDAETA, M.E.M.; BURANI, G.F.; FAGÁ, M.T.W.; OLIVA, C.R.R. La arquitectura para la integración energética y los mercados transfronterizos de energía. In: 5TO CONGRESO LATINOAMERICANO Y DEL CARIBE DE GAS Y ELECTRICIDAD - V LACGEC. Anais. IAPG - Instituto Argentino del Petróleo y del Gas. Buenos Aires - Argentina, 2006. Disponível em: <http://seeds.usp.br/fapesp/03064417/anexo2rtc40110.pdf>.

GIMENES, R.A.V.; UDAETA, M.E.M.; GIMENES, A.L.V.; GRIMONI, J.A.B. Cyber work in energy planning and sustainable development. In: INTERNATIONAL CONFERENCE ON ENGINEERING AND EDUCATION 2007 - ICEE-2007. Proceedings. (http://icee2007.dei.uc.pt/proceedings/). iNEER 2007 / FCTUC (Faculdade de Ciências e Tecnologia da Universidade de Coimbra), Coimbra, Portugal, 2007. Disponível em: <http://seeds.usp.br/fapesp/03064417/anexo2rtc40111.pdf $>$. 


\subsubsection{Nacionais}

UDAETA, M.E.M.; BAITELO, R.L.; GALVÃO, L.C.R.; BERMAN, C. O gerenciamento do lado da demanda e as nuances institucionais e regulatórias na indústria energética. In: V CONGRESSO BRASILEIRO DE PLANEJAMENTO ENERGÉTICO - V CBPE. Anais. SBPE - Sociedade Brasileira de Planejamento Energético. Brasília, 2006. Disponível em: <http://seeds.usp.br/fapesp/03064417/anexo2rtc40112.pdf>.

FUJII, R.J.; UDAETA, M.E.M.; GALVÃO, L.C.R. Modelo de caracterização sistêmica das opções de oferta energética. In: XI CONGRESSO BRASILEIRO DE ENERGIA - XI CBE. Anais. Rio de Janeiro - RJ. COPPE / CHIVAS PRODUÇÕES, 2006. Disponível em: <http://seeds.usp.br/fapesp/03064417/anexo2rtc40113.pdf $>$.

Modelo de avaliação global de recursos energéticos. In: V CONGRESSO BRASILEIRO DE PLANEJAMENTO ENERGÉTICO - V CBPE. Anais. SBPE - Sociedade Brasileira de Planejamento Energético. Brasília, 2006. Disponível em: <http://seeds.usp.br/fapesp/03064417/anexo2rtc40114.pdf>.

MASSARA, V.M.; FAGÁ, M.T.W.; UDAETA, M.E.M. Modelagem de indicadores urbanos para previsão do mercado de gás natural canalizado um exemplo na região metropolitana de São Paulo. In: V CONGRESSO BRASILEIRO DE PLANEJAMENTO ENERGÉTICO - V CBPE. Anais. SBPE - Sociedade Brasileira de Planejamento Energético. Brasília, 2006. Disponível em: <http://seeds.usp.br/fapesp/03064417/anexo2rtc40115.pdf>. 
BAITELO, R.L.; UDAETA, M.E.M.; BURANI, G.F.; GRIMONI, J.A.B. Metodologia para análise e caracterização dos recursos energéticos do lado da demanda. In: V CONGRESSO BRASILEIRO DE PLANEJAMENTO ENERGÉTICO - V CBPE. Anais. SBPE - Sociedade Brasileira de Planejamento Energético. Brasília, 2006. Disponível em: 〈http://seeds.usp.br/fapesp/03064417/anexo2rtc40116.pdf $>$.

UDAETA, M.E.M.; FUJII, R.J.; BAITELO, R.L.; BURANI, G.F. Aplicação da ACC e inclusão dos atores dentro do PIR da região de Araçatuba-SP. In: V CONGRESSO BRASILEIRO DE PLANEJAMENTO ENERGÉTICO - V CBPE. Anais. SBPE - Sociedade Brasileira de Planejamento Energético. Brasília, 2006. Disponível em: <http://seeds.usp.br/fapesp/03064417/anexo2rtc40117.pdf >.

SOARES, F.H.N.; UDAETA, M.E.M.; BIAGUE, M.F. Avaliação do potencial realizável para pequenos aproveitamentos hidroenergéticos na região de Araçatuba no contexto do planejamento integrado de recursos. In: II CONFERÊNCIA DE PCH MERCADO \& MEIO AMBIENTE. Anais. CERPCH - Centro Nacional de Referência em Pequenas Centrais Hidrelétricas. São $\quad$ Paulo, $2006 . \quad$ Disponível em: <http://seeds.usp.br/fapesp/03064417/anexo2rtc40118.pdf $>$.

GENOVESE, A.L.; UDAETA, M.E.M.; GALVÃO, L.C.R. Aspectos energéticos da biomassa como recurso no Brasil e no mundo. In: $6^{\circ}$ CONGRESSO INTERNACIONAL SOBRE GERAÇÃO DISTRIBUÍDA E ENERGIA NO MEIO RURAL - AGRENER GD 2006. Anais. NIPE, Campinas - $\quad$ SP, 2006. Disponível em: 〈http://seeds.usp.br/fapesp/03064417/anexo2rtc40119.pdf $>$. 
REINIG, A.O.; CICONE JR., D.; GALVÃO, L.C.R.; UDAETA, M.E.M. Aplicação do processo de análise hierárquica em conjunto da análise de custos completos para o PIR". In: XII CONGRESSO BRASILEIRO DE ENERGIA - DESAFIOS DO SETOR ENERGÉTICO BRASILEIRO. Anais. Rio de Janeiro. COPPE/UFRJ, 2008. Disponível em: < $\underline{\text { http://seeds.usp.br/fapesp/03064417/anexo2rtc40120.pdf }>}$.

ODONGO, F.C.A.; GRIMONI, J.A.B.; BIAGUE, M.F.; UDAETA, M.E.M. Avaliação dos efeitos na saúde humana do uso dos recursos energéticos dentro do PIR local. In: XII CONGRESSO BRASILEIRO DE ENERGIA - DESAFIOS DO SETOR ENERGÉTICO BRASILEIRO. Anais. Rio de Janeiro. COPPE/UFRJ, 2008. Disponível em: <http://seeds.usp.br/fapesp/03064417/anexo2rtc40121.pdf $>$.

COSTA, F.C.; UDAETA, M.E.M.; GRIMONI, J.A.B.; GALVÃO, L.C.R. Caracterização parcial de recursos de oferta de energia para o planejamento integrado de recursos. In: XII CONGRESSO BRASILEIRO DE ENERGIA - DESAFIOS DO SETOR ENERGÉTICO BRASILEIRO. Anais. Rio de Janeiro. COPPE/UFRJ, 2008. Disponível em: <http://seeds.usp.br/fapesp/03064417/anexo2rtc40122.pdf $>$.

BERNAL, J.L.O.; UDAETA, M.E.M.; GRIMONI, J.A.B.; GALVÃO, L.C.R. Implementação do processo de planejamento integrado de recursos energéticos na região administrativa de Araçatuba no estado de São Paulo. In: VI CBPE - CONGRESSO BRASILEIRO DE PLANEJAMENTO ENERGÉTICO - ENERGIA E MEIO AMBIENTE. Anais. Salvador BA. SBPE, 2008. Disponível em: 〈http://seeds.usp.br/fapesp/03064417/anexo2rtc40123.pdf>. 
GALVÃO, L.C.R.; GRIMONI, J.A.B.; UDAETA, M.E.M.; KANAYAMA, P.H. Planejamento integrado de recursos energéticos como instrumento de desenvolvimento limpo. In: XII Congresso Brasileiro de energia - Desafios do Setor Energético Brasileiro. Anais, Rio de Janeiro. COPPE/UFRJ, 2008. http://seeds.usp.br/fapesp/03064417/anexo2rtc40124.pdf

SADO, I.A.B.; UDAETA, M.E.M.; GALVÃO, L.C.R.; BERNAL, J.L.O. Potencial completo de recursos energéticos de resíduos da biomassa para o PIR da RAA. In: XII CONGRESSO BRASILEIRO DE ENERGIA - DESAFIOS DO SETOR ENERGÉTICO BRASILEIRO. Anais. Rio de Janeiro. COPPE/UFRJ, 2008. Disponível em: 〈http://seeds.usp.br/fapesp/03064417/anexo2rtc40125.pdf $>$.

GALVÃO, L.C.R; UDAETA, M.E.M.; KANAYAMA, P.H.; KATAYAMA, V.T. Procedimentos e valoração completa dos recursos energéticos pelo lado da oferta do planejamento integrado de recursos energéticos. In: XII CONGRESSO BRASILEIRO DE ENERGIA - DESAFIOS DO SETOR ENERGÉTICO BRASILEIRO. Anais. Rio de Janeiro. COPPE/UFRJ, $2008 . \quad$ Disponível em: 〈http://seeds.usp.br/fapesp/03064417/anexo2rtc40126.pdf $>$.

REINIG, A.O.; CICONE JR., D.; GALVÃO, L.C.R.; UDAETA, M.E.M. Ranqueamento de recursos energéticos dentro da análise de custos completos para o PIR. In: VI CBPE CONGRESSO BRASILEIRO DE PLANEJAMENTO ENERGÉTICO - ENERGIA E MEIO AMBIENTE. Anais. Salvador - BA. SBPE, 2008. Disponível em: <http://seeds.usp.br/fapesp/03064417/anexo2rtc40127.pdf $>$. 
UDAETA, M.E.M.; GALVÃO, L.C.R.; BIAGUE, M.F.; BELLACOSA, J.M. Validação sistêmica de procedimentos de busca e coleta in loco de informações energéticas e dos atores En-In para o PIR local. In: XII CONGRESSO BRASILEIRO DE ENERGIA - DESAFIOS DO SETOR ENERGÉtICO BRASILEIRO. Anais. Rio de Janeiro. COPPE/UFRJ, 2008. Disponível em: 〈http://seeds.usp.br/fapesp/03064417/anexo2rtc40128.pdf〉

UDAETA, M.E.M.; GALVÃO, L.C.R.; OLIVEIRA, T.H.; BAITELO, R.L. Valoração de recursos energéticos não-renováveis no âmbito do planejamento integrado de recursos. In: XII CONGRESSO BRASILEIRO DE ENERGIA - DESAFIOS DO SETOR ENERGÉTICO BRASILEIRO. Anais. Rio de Janeiro. COPPE/UFRJ, 2008. Disponível em: <http://seeds.usp.br/fapesp/03064417/anexo2rtc40129.pdf>.

GALVÃO, M.D.; CARNEIRO, P. R.; UDAETA, M.E.M.; GALVÃO, L.C.R. Armazenamento de dados temáticos e formulação e edificação de uma mina de dados. In: XII CONGRESSO BRASILEIRO DE ENERGIA - DESAFIOS DO SETOR ENERGÉTICO BRASILEIRO. Anais. Rio de Janeiro. COPPE/UFRJ, 2008. Disponível em: <http://seeds.usp.br/fapesp/03064417/anexo2rtc40130.pdf>.

\subsection{Artigos em Mídia Aberta da Região (Anexo A3)}

Os artigos foram aqui listados com o intuito de apresentar de forma sinérgica para os En-In elementos de composição do Planejamento Integrado de Recursos energéticos, aplicável ao usual e ao cotidiano da região. É também de interesse demonstrar o suporte dos 
En-In de forma a tornar público o processo de planejamento relativo ao PIRnaUSP, especialmente ao PIR da RAA.

DARIO, M. A. As boas práticas da bioarquitetura. Folha da Região. Araçatuba, p. A2, 9 ago. 2009. Disponível em: <http://seeds.usp.br/fapesp/03064417/anexo3rtc40103.pdf〉.

GALCINO, A. Arquitetura associada ao meio ambiente. Folha da Região. Araçatuba, p. A7, 9 ago. 2009. Disponível em: <http://seeds.usp.br/fapesp/03064417/anexo3rtc40104pdf>.

Energia solar proporciona economia. Folha da Região. Araçatuba, p. A4, 30 ago. 2009. Disponível em: <http://seeds.usp.br/fapesp/03064417/anexo3rtc40107.pdf>.

. Potencial teórico da região é superior ao da hidrelétrica de Nova Avanhandava. Folha da Região. Araçatuba, p. A8, 26 jul. 2009. Disponível em: <http://seeds.usp.br/fapesp/03064417/anexo3rtc40101.pdf>.

Região é propensa à desertificação. Folha da Região. Araçatuba, p. A7, 23 ago. 2009. Disponível em: <http://seeds.usp.br/fapesp/03064417/anexo3rtc40106.pdf>.

. Região tem baixa emissão de gases poluentes, aponta estudo. Folha da Região. Araçatuba, 8 nov. 2009. Disponível em: <http://www.folhadaregiao.com.br/noticia?124420>; <http://seeds.usp.br/fapesp/03064417/anexo3rtc40108.pdf>. 
MANCHETE. Estudo indica soluções energéticas. Folha da Região. Araçatuba, p. A2, 9 ago. 2009. Disponível em: <http://seeds.usp.br/fapesp/03064417/anexo3rtc40102.pdf>.

MANCHETE. Região pode sofrer desertificação. Folha da Região. Araçatuba, p. A2, 23 ago. 2009. Disponível em: <http://seeds.usp.br/fapesp/03064417/anexo3rtc40105.pdf〉.

\subsection{Documentos do Arquivo da Cooperhidro}

COOPERHIDRO. V Simpósio de água e energia. I Conferência sobre Planejamento Integrado de Recursos Energéticos - Região Oeste Paulista. Apresentação. Araçatuba, 2009. Disponível em: <http://seeds.usp.br/fapesp/03064417/anexo4rtc42501.pdf>.

DARIO, M. A. As boas práticas da bioarquitetura. Folha da Região, Araçatuba, 9 ago. 2009, Editorial, p. A2. Disponível em: <http://seeds.usp.br/fapesp/03064417/anexo4rtc42505.pdf〉.

OLIVEIRA, J. Moradores do condomínio Vitória mudam nesta quarta-feira. Folha da Região, Araçatuba, $\quad 8$ mar. $2010 . \quad$ Disponível em: <http://seeds.usp.br/fapesp/03064417/anexo4rtc42506.pdf>.

SILVA, A. S. Aprovação do plano municipal de sustentabilidade. (CMCT\&I) OF. C01, Araçatuba, 2010. Disponível em: 〈http://seeds.usp.br/fapesp/03064417/anexo4rtc42504.pdf〉. 
Plano municipal de sustentabilidade. (CMCT\&I) OF. C01, Araçatuba, 2010. Disponível em: <http://seeds.usp.br/fapesp/03064417/anexo4rtc42503.pdf>.

SOUZA, C. A. F. Desenvolvimento e sustentabilidade. In: VI SIMPÓSIO DE ÁGUA E ENERGIA, Araçatuba, 2010. Disponível em: <http://seeds.usp.br/fapesp/03064417/anexo4rtc42502.pdf>.

TEIXEIRA, S. Famílias trocam Beco da Esperança por condomínio. Folha da Região, Araçatuba, 11 mar. 2010. Disponível em: <http://seeds.usp.br/fapesp/03064417/anexo4rtc42507.pdf>.

Rigesa anuncia instalação de unidade em Araçatuba. Folha da Região, Araçatuba, 2 jun. 2010, p. A7. Disponível em: 〈http://seeds.usp.br/fapesp/03064417/anexo4rtc42508.pdf〉. 


\section{Conclusão}

Os estudos e trabalhos relativos à pesquisa científica em engenharia, acerca de novos instrumentos de planejamento energético para o desenvolvimentos sustentável, intitulado ao longo deste trabalho de PIRnaUSP - Planejamento Integrado de Recursos energéticos -, consiste em essência no desenvolvimento de uma ferramenta metodológica com vista no planejamento energético e na tomada de decisão sustentáveis, de forma a conciliar o máximo de variáveis e parâmetros envolvidos em uma análise sistêmica, holística e racional dos recursos energéticos e da região de estudo.

Na busca de uma completude de análise de sistemas complexos, a estratégia do PIRnaUSP baseia-se em trabalhar esquematicamente as diversas linhas do conhecimento, para que os diferentes enfoques e entendimentos sobre o meio sejam contemplados na integração dos recursos pesquisados (oferta e demanda numa arquitetura orgânica para satisfazer as necessidades de energia sempre). A complexidade de se unificar diversas linguagens e pensamentos determinísticos apresenta-se como o maior desafio do planejamento, e a unicidade da análise pode configurar-se na busca de um bem comum como é o desenvolvimento sustentável.

No entanto, o jargão sustentabilidade, de crescente preocupação desde a década de 1980, apesar de possuir um lugar comum na mídia, nos estudos e nas pesquisas atuais, ocasiona uma supervalorização e certo desentendimento do seu significado. Isso pode ser observado com facilidade nas muitas vertentes do conhecimento, nas quais ainda se configuram linhas divergentes de pensamentos a respeito de propósitos comuns, no longo prazo, que de tão longos implicam mudança de estilo de vida. 
Dessa forma, a sustentabilidade pode ser assimilada como um propósito de bem-estar geral, dentro dos cenários possíveis e das realidades do desenvolvimento social, ou ainda como o condicionamento do ciclo de produção ao mínimo de produtos secundários e à máxima eficiência dos processos e manutenção dos recursos racionalmente otimizados. Esses objetivos estão integrados na busca constante de qualidade de vida e, mais especificamente, pode-se considerá-los propósito do PIR, como um ferramental aplicado sistemicamente para o suprimento das demandas futuras de energia, com a minimização dos impactos socioambientais gerados e o máximo atendimento às necessidades regionais.

A heterogeneidade abordada no escopo do PIR na USP caracteriza a este como holístico, abrangendo especialistas das diversas áreas do conhecimento, expressas na metodologia pelas dimensões estudadas: ambiental, política, social e técnico-econômica. E, no desenvolvimento da metodologia, o emprego de análises técnicas, ferramentas matemáticas, softwares de decisão e gráficos configuram o caráter sistêmico do PIR, que busca nessas duas bases, a completude da análise integrada e do planejamento. Muito porém frisando que o caráter dessa "analise integrada" quando referida ao PIR na USP é concretamente a recursividade sustentável do lado da oferta e do lado da demanda biunivocamente intrínsecos.

Dessa mesma forma, a tese do PIR pode ser observada segundo essas divisões em frentes sinérgicas de trabalho, como a classificação a priori dos Recursos Energéticos do Lado da Demanda (RELDs) e dos Recursos Energéticos do Lado da Oferta (RELOs), que são analisados separadamente, porém sistematicamente, não havendo posterior integração sem uma dessas análises.

Esse aspecto dicotômico do PIR segue sendo observado em todos os níveis dos trabalhos de pesquisa nos quais, em um primeiro momento, existem como produtos isolados. Por conseguinte, trabalha-se a integração com a extinção desse formato bilateral. Citando 
novamente o exemplo dos RELOs, alternativas de geração de energia, e dos RELDs, alternativas baseadas na economia e/ou uso racional do recurso energético, na outra extremidade do ciclo de produção, pode-se observar que, na fase de integração, a classificação perde esse aspecto bilateral e acaba por ser traduzida em um fechamento do ciclo. Assim, ambos são analisados sob mesma metodologia, e o aspecto linear da cadeia produtiva (com começo e fim) passa a ser analisado ciclicamente, expressando um dos conceitos mais difundidos de sustentabilidade (ver Figura 3)

Análise a priori

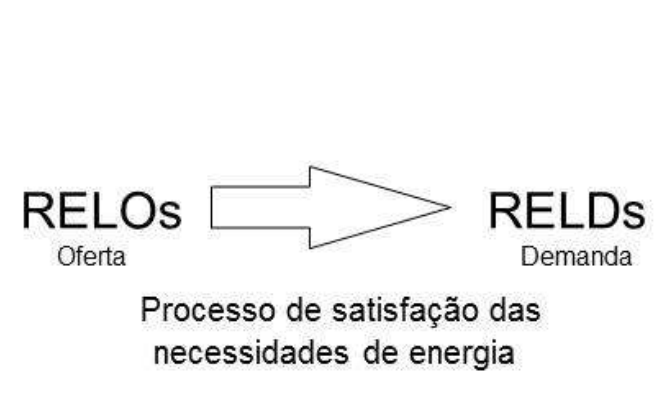

\section{Análise Integrada} Ciclo de atenção em tempo e matéria da
demanda de energia

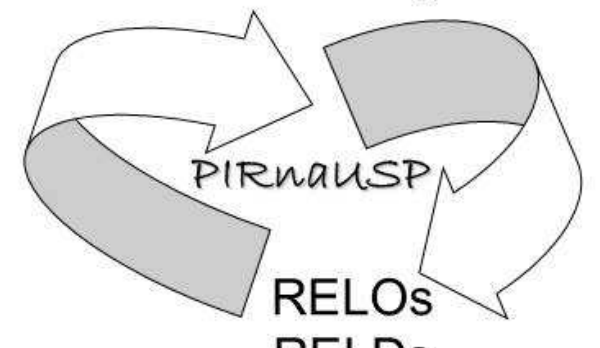

RELDs

\section{Figura 3: Interpretação Livre do PIRnaUSP.}

Outros casos podem ser citados, nos quais a dicotomia das análises do PIR tende a essa consolidação e completamento do ciclo na fase de integração, por exemplo: o mapeamento energoambiental e o CVPC, as ACCs determinística e holística, entre outros exemplos, dentro das especificidades do processo do PIR a partir das suas ferramentas metodológicas. 
Essa classificação ou análise simultânea dos recursos energéticos, de forma que possa haver uma comparação entre seus impactos ambientais, rendimentos e custos completos, permite a unificação das variáveis de influência em uma matriz multicritério de decisão, implementada com o apoio de software de decisão. Dentro do PIR, a essa classificação dá-se o nome de Cômputo e Valoração, enquanto a confecção da matriz multicritério é denominada Análise de Custos Completos (ACC), da qual se utiliza o assim denominado Ranqueamento.

A ACC tem como produto uma classificação ordenada dos recursos energéticos no contexto da realização do Ranqueamento, segundo a preferência na fase de implementação. Essa hierarquização considera o desempenho dos recursos analisados nas diversas áreas do conhecimento, em que foram atribuídos valores quantitativos e qualitativos aos seus atributos, de forma a permitir a comparação.

No entanto, a ACC, como os demais elementos do PIR, tem o caráter dicotômico, que pode ser exemplificada pela ACC Determinística, instruída dentro da metodologia de CVPC do PIR, e, por outro lado, pela a ACC Holística, que considera a opinião dos diversos atores regionais e envolvidos no planejamento. Estes últimos, envolvidos e interessados (En-In), têm grande influência no Ranqueamento dos recursos energéticos e podem representar os beneficiários do planejamento.

Para a hipótese de integração e confecção de plano preferencial, é necessária a determinação de uma região de estudo. No caso, foi escolhida a Região Administrativa de Araçatuba (RAA): localizada no oeste paulista, composta de 43 municípios e polo de produção de energia do estado. Assim, estabeleceu-se um Inventário de informações prévias, com o intuito de caracterizar a região e possibilitar a implementação da metodologia dentro da conjuntura de seus aspectos socioeconômicos e ambientais.

Esse aspecto regional contempla uma classificação municipalizada, na qual é possível identificar municípios com maiores potenciais de implementação das medidas, além de inferir 
sobre uma quantificação do intervalo de atuação entre a situação atual levantada e os limites impostos pela legislação e normas, sejam elas municipais, estaduais ou acordadas em escala global. Esse procedimento evoluiu do Inventário Prévio e, no jargão do PIR, é denominado Mapeamento Energoambiental. Sua caracterização pode gerar ambiguidades e discrepâncias diversas devido à homogeneização de variáveis em escala municipal e ainda às aproximações na escala temporal. No entanto, a sua composição genérica pode ser utilizada dentro da matriz de decisão do PIR e é validada pelo caráter comparativo, quando inter-relacionada com as demais variáveis de Integração de recursos energéticos.

Ainda segundo essa orientação, a caracterização do aspecto regional visa à confecção de cenários futuros, pois sem essas projeções não faria sentido uma ferramenta metodológica de planejamento. Nesse âmbito, com o intuito de manter a abrangência e completude, o PIR tende a demonstrar várias possibilidades futuras para a demanda de energia, em seus diversos usos. Constituídos esses cenários, a empregabilidade da ferramenta metodológica torna-se possível e, dentro da análise completa e integrada, visa-se produzir um plano preferencial de acordo com as hipóteses mais realistas das projeções.

Assim, o modelo de PIRnaUSP, quando do processo de integração, considera as tendências dos cenários futuros, que determinam a demanda a ser satisfeita, o Ranqueamento dos recursos energéticos e respeita as restrições impostas (vigilância permanente de vetoreschave dos meios), sejam elas ambientais, econômicas, sociais ou técnicas. O Plano Preferencial, produto final do Planejamento Integrado de Recursos energéticos, é confeccionado também com a construção de Carteiras de Recursos, que visam metas específicas e discretas que consistem em planos de implementação dos recursos energéticos, especificamente localizados no espaço e no tempo, constituindo horizontes de 50 anos. Nelas também estão contidas todas as ações sugeridas pela metodologia, que podem ser 
implementadas em esferas multidimensionais, seja na forma de grandes empreendimentos energéticos, ou mesmo, em oficinas e pequenas medidas de educação.

Resumidamente, o PIRnaUSP resulta em um plano preferencial que pressupõe ações realizáveis e possíveis aos olhos dos En-In, tal que se define como o somatório dos esforços de todos os atores envolvidos no PIR, explicitando o estado da arte da pesquisa em longo prazo, com o intuito de acolher a todos os diferentes reclames socioambientais e políticos, atuais e futuros, assumindo intrinsecamente o quesito difuso de assegurar a qualidade de vida às gerações dentro do terceiro milênio quando matutado o PIRnaUSP através dos trabalhos e seus produtos e resultados do PIR da RAA. 


\section{Referências Bibliográficas}

1. ANEEL. Atlas de energia elétrica do Brasil. Disponível em: 〈www.aneel.gov.br〉.

2. BAITELO, R. L. Modelo de cômputo e valoração de potenciais completos de recursos energéticos para o planejamento integrado de recursos. 2011. Tese (Doutorado em Engenharia) - Escola Politécnica, Universidade de São Paulo, São Paulo, 2011.

3. . Modelagem completa e análise dos recursos energéticos do lado da demanda para o PIR. 2006. Dissertação (Mestrado em Engenharia) - Escola Politécnica, Universidade de São Paulo, São Paulo, 2006.

4. BERNAL, J. L. O. Modelagem para o aproveitamento sustentável dos biocombustíveis, energia eólica e solar dentro do PIR local: Estudo de caso do PIR da região de Araçatuba. 2009. Dissertação (Mestrado em Energia) - Instituto de Eletrotécnica e Energia, Universidade de São Paulo, São Paulo, 2009.

5. Avaliação prévia para novos instrumentos de planejamento energético regional visando o desenvolvimento sustentável. 2006. Trabalho de Conclusão de Curso (Graduação em Engenharia) - Faculdade de Engenharia do Campus de Guaratinguetá, Universidade Estadual Paulista Júlio de Mesquita Filho, Guaratinguetá, 2006.

6. BIAGUE, M. F. Modelagem da carteira dos recursos energéticos no PIR. Validação do modelo no PIR de Araçatuba. 2010. Tese (Doutorado em Engenharia) - Escola Politécnica, Universidade de São Paulo, São Paulo, 2010.

7. BOARATI, J.H. Um modelo para avaliação ponderada da hidroeletricidade $e$ termeletricidade com gás natural através dos custos completos. 2003. Dissertação 
(Mestrado em Engenharia) - Escola Politécnica, Universidade de São Paulo, São Paulo, 2003.

8. CARVALHO, C. E. A análise do ciclo de vida e os custos completos no planejamento energético. 2000. Dissertação (Mestrado em Engenharia) - Escola Politécnica, Universidade de São Paulo, São Paulo, 2000.

9. CARVAlHO, C. E. Desenvolvimento de procedimentos e métodos para mensuração e incorporação das externalidades em projetos de energia elétrica: Uma aplicação às linhas de transmissão aéreas. 2005. Tese (Doutorado em Engenharia) - Escola Politécnica, Universidade de São Paulo, São Paulo, 2005.

10. CICONE, D.J. Modelagem e aplicação da avaliação de custos completos através do processo analítico hierárquico dentro do planejamento integrado de recursos. 2008. Dissertação (Mestrado em Engenharia) - Escola Politécnica, Universidade de São Paulo, São Paulo, 2008.

11. COOPERHIDRO. I Simpósio de água e energia - Região oeste paulista. Relatório de atividades. Araçatuba, 2004.

Disponível em: <http://seeds.usp.br/fapesp/03064417/anexocoopehidro01.pdf $>$.

12. . II Simpósio de água e energia - Região oeste paulista. Relatório de atividades. Araçatuba, $2006 . \quad$ Disponível em: 〈http://seeds.usp.br/fapesp/03064417/anexocoopehidro02.pdf $>$.

13. . III Simpósio de água e energia - Região oeste paulista. Relatório de atividades. Araçatuba, 2007. Disponível em: <http://seeds.usp.br/fapesp/03064417/anexocoopehidro03.pdf $>$. 
14. IV Simpósio de água e energia - Região oeste paulista. Relatório de atividades.

Araçatuba, 2008 .

Disponível

em:

<http://seeds.usp.br/fapesp/03064417/anexocoopehidro04.pdf $>$.

15. . V Simpósio de água e energia - I Conferência sobre planejamento integrado de recursos energéticos - Região oeste paulista. Apresentação. Araçatuba, 2009. Disponível em: 〈http://seeds.usp.br/fapesp/03064417/anexo4rtc42501.pdf>.

16. COSTA, F. C. Avaliação da cadeia produtiva do biodiesel e seus efeitos na produção e mercado de alimentos através da metodologia PIR - Estudo de caso: região administrativa de Araçatuba. 2008. Trabalho de Conclusão de Curso (Graduação em Engenharia) - Escola Politécnica, Universidade de São Paulo, São Paulo, 2008.

17.21. DOE - DEPARTMENT OF ENERGY (EUA). Renewable energy technology characterizations. Washington, D. C.: Office of Utility Tecnologies, 2000.

18. EDITORIAL. As boas práticas da bioarquitetura. Folha da Região, Araçatuba, p. A2, 9 ago. 2009. Disponível em: 〈http://seeds.usp.br/fapesp/03064417/anexo4rtc42505.pdf>.

19. FUJII, R. J. Modelo de caracterização sistêmica das opções de oferta energética para o PIR. 2006. Dissertação (Mestrado em Engenharia) - Escola Politécnica, Universidade de São Paulo, São Paulo, 2006.

20. FUJII, R. J.; FRANCO, D. G.; UDAETA, M. E. M.; GIMENES, A. L. V. Recursos distribuídos de energia do Estado de São Paulo. 2002. Trabalho de Conclusão de Curso (Graduação em Engenharia) - Escola Politécnica, Universidade de São Paulo, São Paulo, 2002.

21. GENOVESE, A. L. Análise do gás natural liquefeito como alternativa para a segurança do suprimento energético brasileiro. 2007. Trabalho de Conclusão de Curso (Graduação em Engenharia) - Escola Politécnica, Universidade de São Paulo, São Paulo, 2007. 
22. GIMENES, A.L.V. Modelo de integração de recursos como instrumento para um planejamento energético sustentável. 2004. Tese (Doutorado em Engenharia) - Escola Politécnica, Universidade de São Paulo, São Paulo, 2004.

23. GOLDEMBERG, J. Energia, meio ambiente \& desenvolvimento. São Paulo: Edusp, 1998.

24. IWAMOTO, F; POSSARI, R. A. J. Análise da bioenergia da RAA através do PIR Estudo de caso: levantamento de usinas para integração de recursos na região administrativa de Araçatuba. 2009. Trabalho de Conclusão de Curso (Graduação em Engenharia) - Escola Politécnica, Universidade de São Paulo, São Paulo, 2009.

25. KANAYAMA, P.H. Mecanismos de desenvolvimento limpo no planejamento integrado de recursos energéticos. 2007. Tese (Doutorado em Engenharia) - Escola Politécnica, Universidade de São Paulo, São Paulo, 2007.

26. LEAP - LONG-RANGE ENERGY ALTERNATIVES PLANNING SYSTEM. User guide for version 2000. Boston: Boston Center - Tellus Institute, 2001.

27. MELLO, F. M. Inventário dos impactos ambientais provenientes de empreendimentos energéticos na região administrativa de Araçatuba-SP. 2009. Trabalho de Conclusão de Curso (Graduação em Engenharia) - Escola Politécnica, Universidade de São Paulo, São Paulo, 2009.

28. NISHIMARU, R. S. Opções energéticas de pico-geração na RDS Mamirauá. 2003. Trabalho de Conclusão de Curso (Graduação em Engenharia) - Escola Politécnica, Universidade de São Paulo, São Paulo, 2003.

29. OLIVEIRA, J. Moradores do condomínio Vitória mudam nesta quarta-feira. Folha da Região. $\quad 2010 . \quad$ Disponível em: <http://seeds.usp.br/fapesp/03064417/anexo4rtc42506.pdf>. 
30. PICCHI, A. R. Análise, mitigação e potencialização dos impactos e efeitos ambientais causados por usinas termoelétricas a gás natural em grandes metrópoles/cidades. 2006. Trabalho de Conclusão de Curso (Graduação em Engenharia) - Escola Politécnica, Universidade de São Paulo, São Paulo, 2006.

\section{PROCEL - PROGRAMA NACIONAL DE CONSERVAÇÃO DE ENERGIA} ELÉTRICA. Brasília: Eletrobras - Ministério de Minas e Energia. Disponível em: $<$ http://www.eletrobras.gov.br/procel/>.

32. REIS, L. B. D. Geração de energia elétrica - Tecnologia, inserção ambiental, planejamento, operação e análise de viabilidade. Barueri: Editora Manole, 2003.

33. REINIG, A. O. Aplicação da análise de custos completos no PIR visando o gás natural e outros energéticos não renováveis para a região administrativa de Araçatuba. 2008. Trabalho de Conclusão de Curso (Graduação em Engenharia) - Escola Politécnica, Universidade de São Paulo, São Paulo, 2008.

34. RODRIGUES, R. G. B. Análise do cenário atual de demanda do gás natural - Carteira de recursos energéticos visando o gás natural dentro do PIR da região de Araçatuba. 2007. Trabalho de Conclusão de Curso (Graduação em Engenharia) - Escola Politécnica, Universidade de São Paulo, São Paulo, 2007.

35. RTC/PIRNAUSP - $\mathrm{N}^{\mathrm{o}}$ 402. Inventário energoambiental da região administrativa de Araçatuba, nos meios antrópico, aéreo, aquático e terrestre, definidos no PIR, visando os impactos globais dos empreendimentos energéticos. 2009. Relatório técnico-científico. FAPESP $\mathrm{n}^{\mathrm{o}}$ 03/06441-7. USP $\quad-\quad$ SP, 2009. Disponível em: <http://seeds.usp.br/fapesp/03064417/rtcpirnausp402.pdf $>$. 
36. RTC/PIRNAUSP - No 403. Sistema geoenergético aplicado ao PIR. Relatório técnicocientífico. FAPESP $\mathrm{n}^{\mathrm{o}}$ 03/06441-7. USP $\quad$ - SP, 2009. Disponível em: <http://seeds.usp.br/fapesp/03064417/rtcpirnausp403.pdf $>$.

37. RTC/PIRNAUSP - $\mathrm{N}^{\mathrm{o}}$ 404. Valoração dos recursos energéticos pelo lado da oferta utilizados no PIR - Dimensão técnico-econômica. Relatório técnico-científico. FAPESP $\mathrm{n}^{\circ}$ 03/06441-7. USP $\quad-\quad$ SP, 2009. Disponível em: <http://seeds.usp.br/fapesp/03064417/rtcpirnausp404.pdf $>$.

38. RTC/PIRNAUSP - $\mathrm{N}^{\mathrm{o}}$ 405. Valoração dos recursos energéticos pelo lado da oferta utilizados no PIR - Dimensão social. Relatório técnico-científico. FAPESP nº 03/064417. USP $\quad-\quad$ SP, $2009 . \quad$ Disponível em: < $\underline{\text { http://seeds.usp.br/fapesp/03064417/rtcpirnausp405.pdf }>\text {. }}$

39. RTC/PIRNAUSP - $\mathrm{N}^{\mathrm{o}}$ 406. Valoração dos recursos energéticos pelo lado da oferta utilizados no PIR - Dimensão ambiental. Relatório técnico-científico. FAPESP $\mathrm{n}^{\circ}$ 03/06441-7. USP $\quad-\quad$ SP, $2009 . \quad$ Disponível em: 〈http://seeds.usp.br/fapesp/03064417/rtcpirnausp406.pdf>.

40. RTC/PIRNAUSP - $\mathrm{N}^{\mathrm{o}}$ 407. Valoração dos recursos energéticos pelo lado da oferta utilizados no PIR - Dimensão política. Relatório técnico-científico. FAPESP $\mathrm{n}^{\circ}$ 03/06441-7. USP - $\quad$ SP, $2009 . \quad$ Disponível em: 〈http://seeds.usp.br/fapesp/03064417/rtcpirnausp407.pdf>.

41. RTC/PIRNAUSP - $\mathrm{N}^{\circ}$ 408. Valoração dos recursos energéticos do lado da demanda no PIR. Relatório técnico-científico. FAPESP nº 03/06441-7. USP - SP, 2009. Disponível em: 〈http://seeds.usp.br/fapesp/03064417/rtcpirnausp408.pdf>. 
42. RTC/PIRNAUSP $-\mathrm{N}^{\circ}$ 409. Mapeamento energoambiental de indicadores para o PIR da RAA. Relatório técnico-científico. FAPESP nº 03/06441-7. USP - SP, 2009. Disponível em: 〈http://seeds.usp.br/fapesp/03064417/rtcpirnausp409.pdf> .

43. RTC/PIRNAUSP - $\mathrm{N}^{\circ}$ 410. Primeiro balanço energoambiental regional para a RAA/SP 2009 (ano-base 2008). Relatório técnico-científico. FAPESP nº 03/06441-7. USP - SP, 2009. Disponível em: 〈http://seeds.usp.br/fapesp/03064417/rtcpirnausp410.pdf〉.

44. RTC/PIRNAUSP $-\mathrm{N}^{\circ}$ 412. Plano preferencial integrado de recursos energéticos da RAA. Relatório técnico-científico. FAPESP no 03/06441-7. USP - SP, 2009. Disponível em: 〈http://seeds.usp.br/fapesp/03064417/rtcpirnausp412.pdf>.

45. RTC/PIRNAUSP - $\mathrm{N}^{\circ}$ 411. Plano de negócios para os recursos energéticos da RAA. Relatório técnico-científico. FAPESP nº 03/06441-7. USP - SP, 2009. Disponível em: <http://seeds.usp.br/fapesp/03064417/rtcpirnausp411.pdf $>$.

46. SAATY, T. L. Método de análise hierárquica. Nova York/São Paulo: McGrawHill/Makron Books do Brasil Editora, 1991.

47. SABBAG, M. G. Produção do uso sustentável do biodiesel integrado a usinas do setor sucroalcooleiro - Piloto de empreendimento-modelo. 2006. Trabalho de Conclusão de Curso (Graduação em Engenharia) - Escola Politécnica, Universidade de São Paulo, São Paulo, 2006.

48. SADO, I. A. Comparação entre os desempenhos ambientais da gasolina e do etanol para a situação brasileira usando a técnica de avaliação de ciclo de vida In: V CONGRESSO BRASILEIRO DE P\&D EM PETRÓLEO E GÁS, 2008, Fortaleza. Anais. 2008.

Disponível em:

<http://www.iee.usp.br/biblioteca/producao/2009/Trabalhos/sadocomparacao.pdf $>$. 
49. SAUER, I. L.; UDAETA, M. E. M.; GIMENES, A. L. V.; GALVÃO, L. C. R.; CARVALHO, C. E. Brazilian energy prospects seeking the sustainable development. In: IAEE EUROPEAN CONFERENCE, 2003.

50. SAUER, I. Estudo de planejamento integrado de recursos para o sistema elétrico de Boa Vista - RR. Instituto de Eletrotécnica e Energia da Universidade de São Paulo, São Paulo, 2004. Disponível em: 〈http://professorildosauer.files.wordpress.com/2010/01/8-relatorioda-pesquisa-pir2.pdf>.

51. SECRETARIA DE ECONOMIA E PLANEJAMENTO DO ESTADO DE SÃO PAULO. Uma proposta de agenda para 2020: Região administrativa de Araçatuba. São Paulo, 2001.

52. SERGIO, F. A. A. Arquitetura e implementação do modelo computacional energético de mina de dados para o planejamento energético. 2007. Trabalho de Conclusão de Curso (Graduação em Engenharia) - Escola Politécnica da USP, Universidade de São Paulo, São Paulo, 2007.

53. SHIMANOE, B. K. K. Mapeamento e cálculo completo dos potenciais teóricos, realizáveis e do mercado dos recursos energéticos do lado da oferta para o PIR da RAA. 2007. Trabalho de conclusão de curso (Graduação em Engenharia) - Escola Politécnica, Universidade de São Paulo, São Paulo, 2007.

54. DA SILVA, A. S. Plano municipal de sustentabilidade (CMCT\&I) OF. C01. Araçatuba, 2010. Disponível em: 〈http://seeds.usp.br/fapesp/03064417/anexo4rtc42503.pdf〉.

55. DA SILVA, A. S. Aprovação do plano municipal de sustentabilidade (CMCT\&I) OF. C01. 2010 Araçatuba, Disponível em: <http://seeds.usp.br/fapesp/03064417/anexo4rtc42504.pdf $>$. 
56. DE SOUZA, C.A.F. Desenvolvimento e sustentabilidade. In: VI SIMPÓSIO DE ÁGUA E ENERGIA, $\quad 2010 . \quad$ Disponível em: <http://seeds.usp.br/fapesp/03064417/anexo4rtc42502.pdf>.

57. SOUZA, J. R. Tutela jurídica dos recursos hídricos vinculada ao projeto: novos instrumentos de planejamento energético regional visando o desenvolvimento sustentável. 2008. Trabalho de Conclusão de Curso (Graduação de Engenharia) - Centro Universitário Toledo, Araçatuba, 2008.

58. TEDALDI, A.M.; BERNAL, J.L.O; UDAETA, M.E.M; GRIMONI, J.A.B. Balanço Energo-Ambiental para a região administrativa de Araçatuba/SP 2009 - Ano-base 2008. Araçatuba, 2010. ISBN 978-85-86923-23-4.

59. TEIXEIRA, S. Famílias trocam Beco da Esperança por condomínio. Folha da Região. Araçatuba, 2010. Disponível em: <http://seeds.usp.br/fapesp/03064417/anexo4rtc42507.pdf $>$.

60. TEIXEIRA, S. Rigesa anuncia instalação de unidade em Araçatuba. Folha da Região. Araçatuba, p. A7, 2 jun. 2010. Disponível em: <http://seeds.usp.br/fapesp/03064417/anexo4rtc42508.pdf $>$.

61. UDAETA, M.E.M. Planejamento integrado de recursos energéticos para o setor elétrico - PIR - Pensando o desenvolvimento sustentável. 1997. Tese (Doutorado em Engenharia) - Escola Politécnica, Universidade de São Paul, São Paulo, 1997.

62. UDAETA, M.E.M.; GIMENES, A.L.V.; GALVÃO, L.C.R.; REIS, L.B.; CARVALHO, C.E. Brazilian energy outlook for the next five years: A critical overview about energy economics and forecasts. In: 18TH WEC - WORLD ENERGY CONGRESS, 21-25 out. 2001, Buenos Aires. 
63. UDAETA, M.E.M.; GIMENES, A.L.V.; GALVÃO, L.C.R.; CARVALHO, C.E. Power production with natural gas under the concept of the local IRP application. In: $25 \mathrm{TH}$ INTERNATIONAL ASSOCIATION OF ENERGY ECONOMICS - IAEE INTERNATIONAL CONFERENCE, 26-29 jun. 2002, Aberdeen.

64. UDAETA, M.E.M.; GALVÃO, L.C.R. Alternativas energéticas do oeste paulista. Artigo técnico. In: X CONGRESSO BRASILEIRO DE ENERGIA, COPPE/UFRJ, Rio de Janeiro, 2004.

65. UDAETA, M.E.M.; GRIMONI, J.A.B. Modelo institucional do setor elétrico. Relatório técnico. Departamento de Energia e Automação da Escola Politécnica da Universidade de São Paulo. São Paulo, 2004.

66. UDAETA, M.E.M.; RIBEIRO, F.S. Novos instrumentos de planejamento energético regional visando o desenvolvimento sustentável. Relatório Técnico da Etapa 1. São Paulo, 2004.

67. UDAETA, M.E.M.; GALVÃO, L.C.R. Avaliação prévia do PIR para uma reserva de desenvolvimento sustentável. Artigo técnico. In: X CONGRESSO BRASILEIRO DE ENERGIA, COPPE/UFRJ, Rio de Janeiro, 2004.

68. UDAETA, M.E.M.; GALVÃO, L.C.R. Elementos de planejamento integrado de recursos energéticos. Artigo técnico. In: X CONGRESSO BRASILEIRO DE ENERGIA, COPPE/UFRJ, Rio de Janeiro, 2004.

69. UDAETA, M. E.M.; GIMENES, A. L. V.; GALVÃO, L.C.R; BAITELO, R.L. Estado de arte e síntese dos trabalhos realizados no GEPEA acerca do PIR na Fase II. Relatório técnico. Escola Politécnica da Universidade de São Paulo, 2004.

70. UDAETA, M.E.M. et al. Sistema de análise energética para os usos finais no estado de São Paulo. Relatórios 1, 2 e 3. Pesquisa para SESP e CTEEP. São Paulo, 2006. 
71. UDAETA, M.E.M.; BAITELO, R.L. Aspectos políticos do gerenciamento do lado da demanda. In: CBR - CONGRESSO BRASILEIRO DE REGULAÇÃO, Manaus, 2005.

72. UDAETA, M.E.M.; BAITELO, R.L. Aspectos políticos do gerenciamento do lado da demanda. In: CBR - CONGRESSO BRASILEIRO DE REGULAÇÃO, Manaus, 2005.

73. UDAETA, M.E.M.; BAITELO, R.L. Aspectos políticos do gerenciamento do lado da demanda. In: CBR - CONGRESSO BRASILEIRO DE REGULAÇÃO, Manaus, 2005.

74. UDAETA, M.E.M. et alii. Relatório técnico-científico parcial 1. Relatórios de Visitas em Araçatuba, Departamento de Energia e Automação Elétricas, Universidade de São Paulo, São Paulo, 2006.

75. UDAETA, M.E.M. et alii. Relatório técnico-científico parcial 1. Oficina de PIR treinamento técnico, dimensão ambiental. Departamento de Energia e Automação Elétricas, Universidade de São Paulo, São Paulo, 2006.

76. UDAETA, M.E.M. et alii. Relatório técnico-científico parcial 1. Oficina de PIR treinamento técnico, dimensão social. Departamento de Energia e Automação Elétricas, Universidade de São Paulo, São Paulo, 2006.

77. UDAETA, M.E.M. et alii. Relatório técnico-científico parcial 1. Guia de Dados - Projeto FAPESP nº3/06441-7. Departamento de Energia e Automação Elétricas, Universidade de São Paulo, 2006.

78. UDAETA, M.E.M. et alii. Relatório técnico-científico parcial 1. Mina de Dados - Projeto FAPESP n03/06441-7. Departamento de Energia e Automação Elétricas, Universidade de São Paulo, São Paulo, 2006.

79. UDAETA, M.E.M. et alii. Relatório técnico-científico parcial 1. Georreferenciamento Projeto FAPESP nº3/06441-7. Departamento de Energia e Automação Elétricas, Universidade de São Paulo, São Paulo, 2006. 
80. UDAETA, M.E.M. et alii. Relatório técnico-científico parcial 1. Guia de Dados - Projeto FAPESP nº3/06441-7. Departamento de Energia e Automação Elétricas, Universidade de São Paulo, São Paulo, 2006.

81. UDAETA, M.E.M. et alii. Relatório técnico-científico parcial 1. Inventário Ambiental Projeto FAPESP nº3/06441-7. Departamento de Energia e Automação Elétricas, Universidade de São Paulo, São Paulo, 2006.

82. UDAETA, M.E.M. et alii. Relatório técnico-científico parcial 1. AHP e Decision Lens Projeto FAPESP nº3/06441-7. Departamento de Energia e Automação Elétricas, Universidade de São Paulo, São Paulo, 2006.

83. UDAETA, M.E.M. et alii. Relatório técnico-científico parcial 1. Cálculo de Potenciais Energéticos - Projeto FAPESP nº3/06441-7. Departamento de Energia e Automação Elétricas, Universidade de São Paulo, São Paulo, 2006.

84. UNDP. World energy assessment: energy and the challenge of sustainability. Nova York: United Nations Development Programme, 2000.

85. UDAETA, M.E.M.; BAITELO, R.L. Aspectos políticos do gerenciamento do lado da demanda. In: CBR - CONGRESSO BRASILEIRO DE REGULAÇÃO, Manaus, 2005.

86. UDAETA, M.E.M., et alii. Relatório técnico-científico parcial 2 (na versão completa). Departamento de Energia e Automação Elétricas, Universidade de São Paulo, São Paulo, 2008. 